\title{
Simulations and Optimization of Combined Fe- and Cu-Zeolite SCR Monolith Catalysts
}

\author{
Bijesh M. Shakya, Michael P. Harold ${ }^{1}$, and Vemuri Balakotaiah ${ }^{2}$ \\ Department of Chemical \& Biomolecular Engineering \\ University of Houston, Houston, TX 77204-4004, USA
}

\begin{abstract}
$\mathrm{Cu}$-based SCR catalysts exhibit higher activity at lower temperatures $\left(<350{ }^{\circ} \mathrm{C}\right)$ while Fe-based catalysts are more active at higher temperatures under "standard" SCR condition $\left(\mathrm{NH}_{3}+\mathrm{NO}+\mathrm{O}_{2}\right)$. The combination of $\mathrm{Fe}$ - and $\mathrm{Cu}$-based SCR provides a viable solution to expand the temperature window of high NOx conversion. A simulation study of combined Fe/Cu SCR catalyst is carried to: (i) compare the performance of the dual-layer and dual-brick catalysts for different proportions of $\mathrm{Fe}$ - and $\mathrm{Cu}$-zeolite catalysts, (ii) identify the optimal catalyst (washcoat) loadings of individual components in each configuration, and (iii) identify the superior design. The simulations show that there is an optimal fraction of $\mathrm{Fe}$ and $\mathrm{Cu}$ loadings in the combined systems. The optimal fraction of the Fe-zeolite washcoat in the dual-layer catalyst is lower than that in the dual-brick design. It is shown that the dual-brick configuration gives a higher overall NO conversion performance for most conditions. The main cause for the inferior performance of the dual-layer catalyst is the diffusional limitation that lowers the NO conversion at the intermediate temperatures. In this temperature range the $\mathrm{Cu}-\mathrm{SCR}$ catalyst is more active than the Fe-SCR catalyst, so not surprisingly diffusional limitations become more severe for the $\mathrm{Cu}$ catalyst. As a result, the Fe-SCR top layer in the dual-layer architecture creates an additional barrier, lowering the apparent activity of the $\mathrm{Cu}-\mathrm{SCR}$. Because the activity of the combined system is largely contributed by $\mathrm{Cu}-\mathrm{SCR}$ at intermediate temperatures, the NO conversion of the combined system is lowered. This performance decrease due to the addition of the Fe-SCR layer overshadows its benefits at higher temperatures. In the dual-brick configuration, this adverse effect due to diffusional resistance is not as detrimental.
\end{abstract}

Keywords

Combined Fe/Cu-SCR catalyst, Dual-layer, Dual-brick, Standard SCR, Fe-ZSM-5, Cu-Chabazite

\footnotetext{
${ }^{1}$ Corresponding author: Tel.: +1 713743 4322; Fax: +1 713743 4323; Email: mharold@uh.edu (M. P. Harold)

${ }^{2}$ Corresponding author: Tel.: +1 713743 4318; Fax: +1 713743 4323; Email: bala@uh.edu (V. Balakotaiah)
} 


\section{Introduction}

Selective catalytic reduction (SCR) with ammonia is one of the proven technologies for the reduction of nitrogen oxides (NOx) in lean (excess oxygen) environment that is extensively encountered in both stationary and mobile applications. SCR applied to the aftertreatment system of the diesel engines typically utilizes iron- or copper-exchanged zeolite catalysts on monolith substrate [1-5]. Other catalytic materials such as vanadia-based $\mathrm{SCR}\left(\mathrm{V}_{2} \mathrm{O}_{5} / \mathrm{WO}_{3}-\mathrm{TiO}_{2}\right)$ have also been studied for the vehicular applications $[6,7]$. The NOx in the diesel exhaust generally contains a much higher fraction of $\mathrm{NO}$ compared to $\mathrm{NO}_{2}$ [8]. Therefore, one of the main reactions occurring in the SCR system is the so-called standard SCR reaction $\left(\mathrm{NH}_{3}+\mathrm{NO}+\mathrm{O}_{2}\right)$. The performance of the SCR catalyst can be improved by introducing $\mathrm{NO}_{2}$ in the feed which is usually achieved by placing an oxidation catalyst upstream of the SCR catalyst $[4,8]$. In the presence of equimolar $\mathrm{NO}_{2}\left(\mathrm{NO}_{2} / \mathrm{NOx}=0.5\right)$, the fast $\mathrm{SCR}$ reaction becomes dominant which is known to be much faster than the standard SCR reaction $[3-5,7,9,10]$. However, there remains an incentive to lower the precious metal content in the oxidation catalyst and achieve high NOx conversion in the presence of low $\mathrm{NO}_{2}$ concentration [8].

It is well known that $\mathrm{Cu}$-based SCR catalyst, especially $\mathrm{Cu}-\mathrm{Chabazite}(\mathrm{CHA})$ in the form of Cu-SSZ-13 or Cu-SAPO-34, gives high NOx conversion under standard SCR reaction conditions at lower temperatures (ca. $200{ }^{\circ} \mathrm{C}$ ) compared to Fe-ZSM-5 catalysts [2, 8, 11]. It is also less sensitive to the $\mathrm{NO}_{2}$ concentration than the Fe-based catalyst. However, at higher temperatures $\left(>400{ }^{\circ} \mathrm{C}\right)$, the rate of undesired $\mathrm{NH}_{3}$ oxidation by $\mathrm{O}_{2}$ in $\mathrm{Cu}-\mathrm{CHA}$ becomes significantly faster than the desirable standard SCR reaction, resulting in lower NOx conversion $[2,3,11]$. On the other hand, at such high temperatures, Fe-ZSM-5 catalyst gives high NOx conversion [3]. The differences in activities of the two metal-exchanged SCR catalysts provide 
an opportunity to widen the operating temperature range by combining these catalysts. Such benefits of integrating different SCR catalysts (Fe-, $\mathrm{Cu}$ - and V-based catalysts) to achieve higher NOx conversion over wider temperature range has been explored in the literature $[3,8,12,13]$. Kröcher and Elsener[13] studied various combinations of $\mathrm{V}_{2} \mathrm{O}_{5} / \mathrm{WO}_{3}-\mathrm{TiO}_{2}, \mathrm{Fe}-\mathrm{ZSM}-5$ and $\mathrm{Cu}-$ ZSM-5 monolithic catalysts in series (with equal monolith volumes) to attain higher NOx conversion and $\mathrm{N}_{2}$ selectivity. They reported higher activities in terms of NOx conversion in the temperature range of $200{ }^{\circ} \mathrm{C}-700{ }^{\circ} \mathrm{C}$ could be obtained when Fe-ZSM-5 monolith was placed in front of Cu-ZSM-5. Placing the Fe-brick upstream of the $\mathrm{Cu}$-brick minimized the undesirable $\mathrm{NH}_{3}$ oxidation reaction at high temperatures and lowered the $\mathrm{N}_{2} \mathrm{O}$ selectivity. Girard et al. [12] carried out a comprehensive study of the dual-brick Fe-Cu SCR catalyst. Specifically, they investigated the effects of $\mathrm{Fe}: \mathrm{Cu}$ ratio (volume fraction) with different $\mathrm{NH}_{3}: \mathrm{NO}$ ratios and space velocities. For the cases studied $(\% \mathrm{Fe}=0,33,67)$, they found that at steady-state $33 \%$ Fe-zeolite followed by $67 \% \mathrm{Cu}$-zeolite gave the highest overall $\mathrm{NOx}$ conversion over the temperature range studied $\left(175{ }^{\circ} \mathrm{C}-600{ }^{\circ} \mathrm{C}\right)$. Recently, Metkar et al. [8] synthesized a series of dual-layer Fe-Cu catalysts with different washcoat loadings of the individual components. They found that coating a thin layer of Fe-ZSM-5 on top of Cu-ZSM-5 gave improved NOx conversion under steadystate standard SCR reaction conditions. Similar to the dual-brick configuration, the thin layer of Fe catalyst in the dual-layer catalyst improved the NOx conversion at the higher temperatures by suppressing the $\mathrm{NH}_{3}$ oxidation side reaction. In the same study, they speculated that a dual-layer catalyst would be a better design than a dual-brick. They argued that distributing both the Fe and $\mathrm{Cu}$ washcoat over the entire monolith in the dual-layer catalyst would lead to lower diffusional barrier in the individual layer because of the resulting thinner washcoat compared to the dualbrick catalyst for a given catalyst loading and monolith volume. Consequently, this would result 
in a higher overall activity. However, this was not shown experimentally. In another study, Metkar et al. [3] developed global kinetic models for Fe-ZSM-5 and Cu-CHA catalysts. They used the model to qualitatively predict the trends observed in the dual-layer and dual-brick $\mathrm{Fe} / \mathrm{Cu}$ catalysts. However, in that study, they did not perform detailed analysis of the combined system to identify optimal catalyst loading and configuration.

The objective of this study is to advance the earlier studies of Metkar et al. [3] with a detailed analysis of the combined $\mathrm{Fe} / \mathrm{Cu}$ system in order to determine the optimal catalyst loadings and compare the dual-layer and dual-brick catalyst architectures. The paper is organized as follows: First, we review some of the experimental and modeling results previously published. We then carry out simulations with different washcoat fractions of $\mathrm{Fe}$ (or $\mathrm{Cu}$ ) catalyst for both the dual-layer and dual-brick architectures. To this end, we compare the performance of both designs for different catalyst (washcoat) compositions. We also perform an analysis of washcoat diffusional limitations in $\mathrm{Cu}$ - and $\mathrm{Fe}$ - catalyst to order to identify the temperature range over which diffusion in the washcoat becomes controlling. This is essential to determine the conditions under which one configuration performs better than the other. Finally, we carry out sensitivity analyses of key model and operating parameters viz., effective washcoat diffusivity and space velocity to assess the impact of these parameters on the performance of the combined system.

\section{Reactor model}

A (1+1)-D model of a catalytic monolith channel is used in this study [3]. The governing equations consist of species balances in the fluid and washcoat phase, and surface species balances on the catalyst surface within the washcoat. The key assumptions made in the model development are as follows: (i) laminar flow, (ii) convection dominated flow in the fluid phase, 
(iii) isothermal conditions because of low reactant concentration (500 ppm), and (iv) constant physical properties.

The one-dimensional fluid phase species balance consists of accumulation, convection and external mass transfer terms:

$$
\frac{\partial x_{f m, j}}{\partial t}=-\langle u\rangle \frac{\partial x_{f m, j}}{\partial z}-\frac{k_{m e, j}}{R_{\Omega_{1}}}\left(x_{f m, j}-x_{s, j}\right) .
$$

Here, $x_{f m, j}$ and $x_{s, j}$ are the mole fraction of species $j$ in the fluid phase and at the fluid/washcoat interface, respectively. $\langle u\rangle, R_{\Omega_{1}}$ and $k_{m e, j}$ represent the average fluid velocity, hydraulic radius (the ratio of open channel area to channel perimeter) and external mass transfer coefficient, respectively. The external mass transfer coefficient is computed using the asymptotic Sherwood number $\left(\mathrm{Sh}_{\mathrm{e}, \infty}\right)[3]$ :

$$
k_{m e, j}=\frac{S h_{e, \infty} \cdot D_{f, i}}{4 R_{\Omega_{1}}}
$$

where, $D_{f, i}$ is the diffusivity of species $j$ in the gas phase. The gas phase diffusivities were computed using Lennard-Jones potentials [3].

The species balance in the washcoat consists of accumulation, diffusion and reaction terms:

$$
\varepsilon_{w c} \frac{\partial x_{w c, j}}{\partial t}=\frac{\partial}{\partial y}\left(D_{e, j} \frac{\partial x_{w c, j}}{\partial y}\right)+\frac{1}{C_{t m}} \sum_{r=1}^{r x n} \vartheta_{j r} R_{r}\left(\underline{x_{w c}}, \underline{\theta}, T\right) .
$$

Here, $\varepsilon_{w c}, C_{t m}, x_{w c, j}$, and $D_{e, j}$ represent washcoat porosity, total gas concentration in the interstitial space of the washcoat, mole fraction and effective diffusivity of species $j$ in the washcoat, respectively. Similarly, $\vartheta_{j r}$ and $R_{r}$ represent stoichiometric coefficient of species $j$ for reaction $r$ and reaction rate of reaction $r$, respectively. The effective diffusivity $\left(D_{e}\right)$ in the washcoat is estimated by assuming a diffusivity ratio, $\lambda\left(=D_{f} / D_{e}\right)$, of 100 [3]. Metkar et al.,[14] found that a 
diffusivity ratio $(\lambda)$ of $80-100$ gave a good estimate on the onset of the diffusion limitations on similar catalysts. Since effective washcoat diffusivity is an important parameter in this study, we also carried out sensitivity analyses using a lower value of $\lambda=10$.

Similarly, the site balance equation can be written as follows:

$$
\frac{\partial \theta_{k}}{\partial t}=\frac{1}{\Gamma} \sum_{r=1}^{r x n} \vartheta_{k r} R_{r}\left(\underline{x_{w c}}, \underline{\theta}, T\right) .
$$

Here, $\theta_{k}$ represents fractional coverage of surface species $k$ and $\Gamma$ corresponds to active site density or site concentration $\left(\mathrm{C}_{\mathrm{s} 1, \mathrm{Fe},}, \mathrm{C}_{\mathrm{s} 2, \mathrm{Fe}}, \mathrm{C}_{\mathrm{s} 1, \mathrm{Cu}}\right)\left(\mathrm{mol} / \mathrm{m}^{3}{ }_{\mathrm{wc}}\right)$.

The above equations are solved along with following initial and boundary conditions:

$$
\begin{aligned}
& x_{f m, j}=x_{f i n, j}^{o} \\
& t=0: x_{w c, j}=x_{w c, j}^{o} \\
& \theta_{k}=\theta_{k}^{o} \\
& z=0: x_{f m, j}(t)=x_{f m, j}^{i n}(t) \\
& y=0 \quad: k_{m e, j}\left(x_{f m, j}-x_{s, j}\right)=-\left.D_{e, j} \frac{\partial x_{w c, j}}{\partial y}\right|_{x_{w c, j}=x_{s, j}} \quad, \quad, \\
& y=R_{\Omega_{2}}: \frac{\partial x_{w c, j}}{\partial y}=0 .
\end{aligned}
$$

Here, $R_{\Omega_{2}}$ and $x_{s, j}$ correspond to characteristic length scale in washcoat or effective washcoat thickness and concentration of species $j$ at the interface of washcoat and fluid phase, respectively. The values of parameters used in the simulation are provided in Tables 1 and 2 . The above equations were discretized using finite volume discretization scheme which results in a set of ordinary differential equations (ODEs). The ODEs thus obtained are integrated by using backward differentiation formula method (LSODE subroutine in ODEPACK [15])

\section{Kinetic model}


The kinetic models developed by Metkar et al., [3] for Cu-CHA and Fe-ZSM5 were used in this study. The list of reactions along with rate expressions used in the model is provided in Table 3. For detailed description of the model, we refer the readers to the work by Metkar et al., [3]. For completeness, the key elements of the model are summarized below. $\mathrm{NH}_{3}$ is assumed to adsorb predominantly on S1 sites that may correspond to Brønsted acid sites [3]. It has been observed that $\mathrm{NH}_{3}$ inhibits the standard SCR reaction (R4) at lower temperatures over Fe-ZSM5 catalyst [3]. In order to explain this inhibition effects, a second $\mathrm{NH}_{3}$ adsorption site type (S2) was also considered in the Fe-ZSM5 kinetic model and the standard SCR reaction rate expression (R4) was modified by introducing an adsorption term in the denominator of the rate expression (Table 3, R4) [3]. On the other hand, the $\mathrm{NH}_{3}$ inhibition effect on standard SCR reaction over $\mathrm{Cu}-\mathrm{CHA}$ was found to be insignificant and hence only a single adsorption site (S1) was considered [3]. Furthermore, only the reactions $\mathrm{R} 1-\mathrm{R} 8$ were considered for $\mathrm{Cu}-\mathrm{CHA}$ catalyst as the amount of $\mathrm{N}_{2} \mathrm{O}$ formed was negligible above $350{ }^{\circ} \mathrm{C}$, temperatures at which reactions $\mathrm{R} 9$ and R10 becomes important [3]. The kinetic parameters for $\mathrm{Cu}-\mathrm{CHA}$ and Fe-ZSM5 catalysts used in this study are provided in Table 4.

\section{$4 \quad$ Review of experimental and modeling results}

Metkar et al. [8] carried out an extensive experimental study of the combined Fe/Cu SCR catalyst. A series of dual-layer $\mathrm{Fe} / \mathrm{Cu}$ catalysts having a range of metal ratios were synthesized and their performance data were compared under standard and fast SCR reaction conditions. For brevity, we simply refer these catalysts as Fe-SCR and Cu-SCR. In the same study [8] the investigators carried out experiments where catalysts were arranged as sequential bricks. They showed that higher NO conversion can be sustained over wider temperature range either by 
coating a thin layer of Fe-SCR washcoat over the $\mathrm{Cu}$-SCR catalyst or by placing a smaller brick of Fe-SCR monolith upstream of the Cu-SCR brick.

In another study [3], they developed global kinetic models for commercial Fe-ZSM-5 and $\mathrm{Cu}-\mathrm{CHA}$ catalysts. The simulated and experimental steady-state NOx conversion versus temperature is provided in Fig 1 for the standard, fast and $\mathrm{NO}_{2} \mathrm{SCR}$ reaction conditions. These data have been reported in the earlier publication by Metkar et al. [3] and are shown here for completeness. As mentioned, the $\mathrm{Cu}-\mathrm{SCR}$ catalyst gives a higher $\mathrm{NO}$ conversion at lower temperature while the Fe-SCR catalyst is more active at higher temperatures under standard SCR conditions. The lower activity of the $\mathrm{Cu}-\mathrm{SCR}$ catalyst at higher temperature is attributed to the enhanced oxidation of $\mathrm{NH}_{3}$ by $\mathrm{O}_{2}$. It is further noted that the model predictions are most reliable for the standard SCR condition while the model predictions are not as good when $\mathrm{NO}_{2}$ is added to the feed (fast and $\mathrm{NO}_{2} \mathrm{SCR}$ ). The reason is the current kinetic model does not account in detail for the formation and consumption of nitrate species (e.g. $\mathrm{NH}_{4} \mathrm{NO}_{3}(\mathrm{~s})$ ) which is especially important at high $\mathrm{NO}_{2}$ feed concentrations and at lower temperatures [16, 17]. Recently, Colombo et al.[16] developed a detailed kinetic model focusing mainly on the $\mathrm{NO}_{2}$-related chemistries over the $\mathrm{Cu}$-zeolite catalyst. Their model was able to predict most of the transient trends observed during the fast and $\mathrm{NO}_{2} \mathrm{SCR}$ experiments. For the current study, we focus on the standard SCR reaction. It is noted from Fig 1 that the NOx conversions obtained by $\mathrm{Fe}-$ and $\mathrm{Cu}-$ SCR catalysts during fast and $\mathrm{NO}_{2}$-SCR conditions are comparable with Fe-SCR performing slightly better over wider temperatures. Thus, for the catalysts considered, there would not be any significant performance benefit of using a combined $\mathrm{Fe} / \mathrm{Cu}$ catalyst under fast and $\mathrm{NO}_{2}-\mathrm{SCR}$ conditions. 


\section{Working principle of the combined Fe/Cu-SCR catalyst - implications for catalyst design}

Before discussing the results of this study, it is instructive to review the working principle of the combined $\mathrm{Fe} / \mathrm{Cu} \mathrm{SCR}$ catalyst and its implication on catalyst design. The working principle of the combined Fe/Cu-SCR catalyst is based on the different activities of the $\mathrm{Cu}-\mathrm{SCR}$ and Fe-SCR catalysts over the temperature range of interest $[8,12,13]$. Specifically, the $\mathrm{Cu}-$ SCR catalyst exhibits higher standard SCR activity in the lower temperature range $\left(<400{ }^{\circ} \mathrm{C}\right)$ while the Fe-SCR catalyst has higher activity in the high temperature range $\left(>400{ }^{\circ} \mathrm{C}\right)$. The diminished standard SCR activity of $\mathrm{Cu}-\mathrm{SCR}$ catalyst at higher temperatures $\left(>350{ }^{\circ} \mathrm{C}\right)$ is a result of the $\mathrm{NH}_{3}$ oxidation side reaction [8]. As a result, a significant fraction of $\mathrm{NH}_{3}$ is oxidized by $\mathrm{O}_{2}$ rather than $\mathrm{NO}$ leading to the reduced $\mathrm{NO}$ conversion for the $\mathrm{Cu}$-SCR catalyst at higher temperatures. In contrast, the $\mathrm{NH}_{3}$ oxidation activity is comparatively lower on the Fe-SCR catalyst (up to $\mathrm{T}<550{ }^{\circ} \mathrm{C}[8,18]$ ) and, as a result, higher conversion of $\mathrm{NO}$ by $\mathrm{NH}_{3}$ is achieved at higher temperatures. In addition to the kinetics, physical processes viz. external and internal (washcoat) mass transport as well as flow rate (space velocity) also play crucial roles in the determining the performance of the combined system and, ultimately in determining the optimal configuration.

One of the design objectives in the combined $\mathrm{Fe} / \mathrm{Cu}$ catalyst is to minimize the consumption of $\mathrm{NH}_{3}$ via oxidation by $\mathrm{O}_{2}$. At higher temperatures, the reaction rate is confined to the front section of the monolith and in the region of the washcoat in closest contact with the fluid phase. Therefore, placing Fe-SCR catalyst upstream of the Cu-SCR in a dual-brick system or coating a Fe- layer on top of $\mathrm{Cu}$ washcoat minimizes the extent of the $\mathrm{NH}_{3}$ oxidation side reaction in the combined system. With either design, the NO conversion is primarily carried out 
on the Fe-SCR catalyst at higher temperatures. It should also be mentioned that at sufficiently high temperatures (i.e. fast reaction limit) the conversion is largely determined by the transverse Peclet number $(\mathrm{P})$ which is the ratio of transverse diffusion time in the fluid phase and the residence time [19]. Under fast reaction conditions, the characteristic diffusion time from the bulk fluid to the washcoat surface has to be smaller than the residence time in order to achieve the highest conversion of the reactant for the given catalyst loading (active site concentration). In the case of the dual-brick configuration in which a short section/brick of Fe-SCR catalyst is used, the performance is lowered at high space velocity or equivalently, low residence time conditions ( $\mathrm{P} \gg>1$ for Fe brick). On the other hand, at lower temperatures, the Fe- component is essentially inactive and most of the $\mathrm{NO}$ conversion occurs on the $\mathrm{Cu}-\mathrm{SCR}$ catalyst. However, at the intermediate temperatures (ca. $200-350{ }^{\circ} \mathrm{C}$ ) in which a washcoat diffusion limitation becomes important, the dual-layer catalyst may give a lower NO conversion because of the additional diffusive barrier posed by the Fe-SCR washcoat. Such a diminishing effect is expected to be less severe in the case of brick configuration in which the reacting species from fluid phase can readily reach the active $\mathrm{Cu}$ - sites. It is worth mentioning that while it is true that the diffusional limitations in the Fe- layer in the dual-layer catalyst is less severe than for the dual-brick because of the thinner washcoat, this is not entirely valid for the underlying $\mathrm{Cu}$ layer. Even though the thickness of the $\mathrm{Cu}$-SCR washcoat is thinner in dual-layer catalyst, it still suffers from diffusional barrier because of the Fe- layer. This has important implication in terms of catalyst design. We return to this point in more detail below.

\section{$6 \quad$ Results and discussion}

In this section, we present the simulation results for different $\mathrm{Fe} / \mathrm{Cu}-\mathrm{SCR}$ catalysts under standard SCR reaction conditions. First, we compare of the performance of catalysts for different 
washcoat loadings. Then we assess the impact of washcoat diffusion on Fe-SCR and Cu-SCR catalyst in order to identify the temperature range over which diffusion in the washcoat is important. These simulations provide insight about the optimal catalyst loading in the combined catalysts. Finally, simulation results with different washcoat diffusivities and residence times are presented to analyze the sensitivity of these parameters on the calculated NO conversion in the combined system.

\subsection{Simulations of dual-layer and dual-brick Fe/Cu-SCR catalysts}

In this section, we present the simulation results of the dual-layer and dual-brick $\mathrm{Fe} / \mathrm{Cu}$ SCR catalyst. For the purpose of comparison, we define the base case conditions to include a gas hourly space velocity (GHSV) of 57,000 $\mathrm{hr}^{-1}$ (at STP), denoted as SV1, and a diffusivity ratio $\left(\lambda=\mathrm{D}_{\mathrm{f}} / \mathrm{D}_{\mathrm{e}}\right)$ of 100 . One comment is worth making regarding the assumed active site loading values (see Table 3). The loadings reflect that $\mathrm{NH}_{3}$ is stored on both Bronsted and metal sites, and correspond to typical Si/Al ( 25) and metal loading values ( $2.5 \mathrm{wt} . \%)$.

The base case simulations of the dual-layer and dual-brick catalyst for different fractions of Fe- and $\mathrm{Cu}-\mathrm{SCR}$ washcoat loading are given in Fig 2. The fraction of $\mathrm{Fe}$ (or $\mathrm{Cu}$ ) is based on mass fraction of $\mathrm{Fe}$ - (or $\mathrm{Cu}$-) SCR washcoat i.e., $\% \mathrm{Fe}=$ mass of $\mathrm{Fe}-\mathrm{SCR}$ washcoat $/$ total washcoat loading. The metal loadings or the site densities (mol-site $/ \mathrm{m}^{3}{ }_{\text {,wc }}$ ) of $\mathrm{Fe}$ and $\mathrm{Cu}$ in the corresponding washcoat are kept constant. The results are consistent with those reported by Metkar et al. [3]. All the simulations are carried out for a fixed monolith volume and total washcoat loading in order to make comparisons under identical conditions (i.e., same residence time and total washcoat thickness). Thus, differences in the apparent activities of the catalysts are solely because of catalyst architecture and relative washcoat loadings of the $\mathrm{Cu}$ - and $\mathrm{Fe}-\mathrm{SCR}$ catalysts. It can be seen that the combined $\mathrm{Fe} / \mathrm{Cu}-\mathrm{SCR}$ catalysts give $>80 \% \mathrm{NO}$ conversion over 
the temperature range of interest, $\sim 200-600{ }^{\circ} \mathrm{C}$. Expectedly, the simulated NO conversion of the combined system is bounded between the conversions obtained by the individual $\mathrm{Cu}-$ and $\mathrm{Fe}$ SCR catalyst over the entire temperature range. The NO conversion over both the dual-layer and dual-brick combined system is lower than the $\mathrm{Cu}$-only and Fe-only catalysts below and above the temperature of ca. $400{ }^{\circ} \mathrm{C}$, respectively. This temperature corresponds to the point of intersection of the NO conversion plot for $\mathrm{Cu}$ - and Fe-only SCR catalyst (Fig 1a) which will depend on activities (catalyst loading) of the individual catalysts and operating conditions. While both the configurations give reasonable conversion (ca. $>80 \%$ ) over the entire temperature range of interest, a closer inspection reveals that the dual-brick configuration for the same catalyst composition gives a slightly higher NO conversion (Fig 2).

A direct comparison of the predicted NO conversion over the dual-layer and dual-brick catalysts is shown in Fig 3 for the $10 \%$ Fe-SCR catalyst (i.e. $5 \mu \mathrm{m} \mathrm{Fe}+45 \mu \mathrm{m} \mathrm{Cu}$ for dual-layer and $0.2 \mathrm{~cm} \mathrm{Fe}+1.8 \mathrm{~cm} \mathrm{Cu}$ ). We have deliberately chosen combined catalysts with a lower $\mathrm{Fe}$ loading to make the following points. First, at the temperature range of $200-400{ }^{\circ} \mathrm{C}$, the dualbrick gives a higher NO conversion than dual-layer. This is attributed to the emergence of the diffusional limitation in the Cu-SCR washcoat. To verify this claim, we performed simulations with a lower value of diffusivity ratio $\left(\lambda=D_{f} / D_{e}\right)$; i.e., we increased the diffusivity of the species in the washcoat by an order of magnitude. The result is shown in Fig 4. It can be seen that washcoat diffusion becomes important in the $\mathrm{Cu}-\mathrm{SCR}$ catalyst in the temperature of ca. 200 $300{ }^{\circ} \mathrm{C}$ while it becomes significant in the temperature range of ca. $300-500{ }^{\circ} \mathrm{C}$ for the $\mathrm{Fe}-\mathrm{SCR}$ catalyst. This result clearly explains why the dual-layer catalyst gives a lower NO conversion than the dual-brick. The additional barrier created by Fe-SCR washcoat hinders the reacting species from reaching the more active $\mathrm{Cu}-\mathrm{SCR}$ catalyst in the temperature range of $200-300{ }^{\circ} \mathrm{C}$. 
Obviously, such an inert top layer barrier does not exist in the dual-brick catalyst. Metkar et al., [8] studied the effect of washcoat diffusion in the Fe-ZSM-5 catalyst and found it to be important in the temperature range of $300-500{ }^{\circ} \mathrm{C}$ which is consistent with the result shown in this study. Based on this finding, they speculated that, if present, washcoat diffusion in the dual-layer would dominate in this temperature range and therefore the dual-layer catalyst should out-perform the dual-brick catalyst because of the thicker Fe-SCR washcoat in the dual brick catalyst. However, the simulations here show that in the intermediate temperature range $\left(200-300{ }^{\circ} \mathrm{C}\right)$, diffusional limitations are important in the underlying $\mathrm{Cu}-\mathrm{SCR}$ washcoat, and as a result the dual-layer gives a lower NO conversion at these temperatures (Fig 4). On the other hand, at higher temperatures $\left(>500{ }^{\circ} \mathrm{C}\right)$, the dual-layer gives a higher $\mathrm{NO}$ conversion than dual-brick for the catalyst compositions used (Fe- content of 10\%) (Fig 4). As mentioned earlier, at high temperatures, the Fe-SCR catalyst becomes active and the key parameter that determines the conversion is the transverse Peclet number $\left(P=\left(<u>R_{\Omega^{2}}^{2}\right) /\left(L D_{e}\right)\right)$. Clearly, for lower loading (or fraction) of FeSCR catalyst in the combined system, the transverse Peclet number in the Fe-brick is smaller compared to that in dual-layer configuration for which the Fe-SCR washcoat is coated throughout the total monolith length. As a result of the increased contact time, a higher NO conversion is achieved in the dual-layer catalyst than the dual-brick. It should be mentioned that for a higher loading of Fe-SCR catalyst (>20\% Fe), the dual-brick configuration gives a higher NO conversion over the entire temperature range for the conditions studied here (SV1 and $\lambda=100)($ Fig 2).

In order to identify an optimal catalyst loading and make a meaningful comparison of both architectures, it is important to define an objective function that accounts for the performance of the system over the entire temperature range of interest. Therefore, we define our 
objective function (f) as the root mean square of the difference between the NO conversion of the combined system and the maximum NO conversion. The maximum NO conversion is defined as the maximum of the simulated NO conversion attained by individual Cu-SCR and Fe-SCR catalysts for a given temperature i.e.,

$$
f=\frac{\sqrt{\sum\left(\left(X_{N O}^{\max }(T)-X_{N O}^{\text {calc }}(T)\right)\right)^{2}}}{N}
$$

where, $X_{N O}^{\max }(T)=\max \left(X_{N O}^{C u}(T), X_{N O}^{F e}(T)\right)$.

A total of ten simulated data points (NO conversions) were used to evaluate the value of $f$. These correspond to the temperatures at which the experimental data points were available. Fig 5 (a) shows the computed $f$-values as a function of $\%$ Fe-SCR loading in the dual-layer and dual-brick catalyst. The values of the objective function, $f$, computed for both the configurations exhibit a minimum as a function of $\mathrm{Fe}-\mathrm{SCR}$ fraction, clearly indicating an optimal loading. The computed optimal Fe-SCR content for the dual-layer and dual-brick configurations are ca. $10 \%$ (Fe-SCR = $5 \mu \mathrm{m}$, total $=50 \mu \mathrm{m})$ and $20 \%(\mathrm{Fe}-\mathrm{SCR}=0.2 \mathrm{~cm}$, total $=2 \mathrm{~cm})$, respectively. A comparison of NO conversion attained by the optimal dual-layer and dual-brick catalysts is shown in Fig 5 (b). It can be seen that the optimal dual-brick catalyst gives a higher NO conversion than the duallayer counterpart (up to 6\%) for temperatures $>250{ }^{\circ} \mathrm{C}$. This can also be inferred by the computed $f$-value which is lower for the dual-brick catalyst $\left(f_{\text {layer }}=0.022, f_{\text {brick }}=0.014\right)$. It is important to note that the $f$-values obtained for the dual-brick are lower than those for the duallayer over almost the entire range of the catalyst compositions under these operating conditions. The explanation for the inferior performance of the dual-layer catalyst following the earlier discussion is that the diffusive barrier in the Cu-SCR washcoat becomes significant at the 
intermediate temperatures and, as a result, lower NO conversions are obtained in the dual-layer catalyst compared to the dual-brick. The diminished performance of the dual-layer catalyst at these intermediate temperatures overshadows the improvements achieved at the higher temperature. On the other hand, the diffusional limitations are less severe in the dual-brick configuration resulting in comparatively higher activity. Based on these results, it can be concluded that under the conditions considered (GHSV, diffusivity ratios, and catalysts), the dual-brick gives a slightly higher overall NO conversion than the dual-layer catalyst over the temperature range considered $\left(200-600^{\circ} \mathrm{C}\right)$.

\subsection{Effects of effective washcoat diffusivity and space velocity}

In this section, we present the model analyses of the effects of effective washcoat diffusivity and space velocity on the performance of the dual-layer and dual-brick $\mathrm{Fe} / \mathrm{Cu}-\mathrm{SCR}$ catalysts. The effective diffusivity and space velocity are two key parameters that determine the overall performance of the combined system, so it is important to understand how these parameters impact the comparative performance of the dual-layer and dual-brick configurations. Four different cases were considered including two different diffusivity ratios ( $\lambda=10$ and 100) and two different space velocities $\left(\mathrm{SV} 0.5=0.5 \times 570,000 \mathrm{hr}^{-1}\right.$ and SV5 $\left.=5 \times 570,000 \mathrm{hr}^{-1}\right)$. The identified diffusional limitation in the dual-layer catalyst resulted in lower overall NO conversion over the temperature of interest $\left(200-600{ }^{\circ} \mathrm{C}\right)$. So, it is interesting to know the extent to which washcoat diffusion impacts the optimal catalyst configurations. Likewise, it is also important to analyze the impact of residence time or space velocity on the performance of the combined system. Assuming minimal diffusional limitations, we would expect the dual-brick catalyst to give a lower NO conversion for a sufficiently high space velocity. In the dual-brick catalyst, the individual components are accumulated either at the front (Fe-SCR) or at the back (Cu-SCR) 
leading to lower contact time in the individual bricks. On the other hand, for the dual-layer catalyst, both catalytic components are spread over the entire length and comparatively higher overall performance would be expected, provided the diffusional barrier in the washcoat is minimal. It is important to point out that in the limit of no washcoat diffusion, the dual-layer catalyst will behave as a physically-mixed catalyst. The activity of the combined catalyst would then simply be the weighted average of the activities of the individual components as shown experimentally by Metkar et al. [8]. Finally, it should also be emphasized that the full potential of the combined system cannot be realized by physically mixing the $\mathrm{Fe}$ and $\mathrm{Cu}$ SCR catalyst. This is because at higher temperatures, the extent of $\mathrm{NH}_{3}$ oxidation side reaction in physically mixed catalysts will always be higher than in the segregated (dual-layer or dual-brick) catalysts.

Fig 6 shows the computed steady-state NO conversion as a function of temperature for the dual-layer (Fig 6(a and c)) and dual-brick (Fig 6(b and d)) catalysts at both high and low GHSV (SV0.5 and SV5) with the diffusivity ratio ( $\lambda$ ) fixed at 100. The corresponding values of the objective function $(f)$ as a function of Fe-SCR volume (washcoat) fraction are shown in Fig 7. Expectedly, the NO conversion for both dual-layer and dual-brick catalysts increase when the space velocity (residence time) is decreased (increased) (compare Fig 6a and 6b). For the duallayer catalyst, the $\mathrm{NH}_{3}$ oxidation side reaction becomes more significant at higher temperatures leading to lower NO conversion (compare Fig 6a to 6b). On the other hand, because of the lower space velocity (or smaller transverse Peclet number), the reaction is almost complete in the FeSCR brick for temperatures $>400{ }^{\circ} \mathrm{C}$ in the dual-brick configuration (Fig 6b). Since the $\mathrm{NH}_{3}$ oxidation reaction is not as significant in the Fe-SCR catalyst as in the Cu-SCR catalyst, high NO conversion is achieved at the higher temperature (Fig 6(b)). This leads to an overall superior performance for the dual-brick catalyst compared to the dual-layer as evidenced by the values of 
the objective function $f$ shown in Fig 7(a). In contrast, at high space velocity (SV5=5×57,000 $\mathrm{hr}^{-}$ ${ }^{1}$ ), both the combined catalysts give an overall activity that is lower than that of the single $\mathrm{Cu}$ SCR catalyst, which can be inferred by the monotonically increasing values of the objective function, $f$, as the percent content of the Fe-SCR catalyst is increased over the entire range of catalyst composition. The negative effect of the high space velocity is clearly more pronounced in the dual-layer catalysts. Indeed, it can be seen in Fig 6(c) that the NO conversion attained by the dual-layer catalyst is significantly reduced in the temperature range of $200-500{ }^{\circ} \mathrm{C}$. At these temperatures, the NO conversion activity is largely provided by the underlying $\mathrm{Cu}-\mathrm{SCR}$ washcoat but the reactants have to diffuse through the comparatively inactive Fe-SCR layer. Because of the high space velocity or low residence time, the reactants do not reach the active underlying $\mathrm{Cu}$-SCR catalyst and therefore, the performance of the dual-layer catalyst is drastically reduced. In contrast, the adverse impact of high space velocity is comparatively less severe in dual-brick than in dual-layer as shown in Fig 6(d) and Fig 7(b).

In order to assess the impact of the washcoat diffusivity on the catalyst performance and its implication in identifying optimal catalyst architecture, the above simulations were repeated using a lower diffusivity ratio $(\lambda)$ of 10 . The simulation results are shown in Fig.8. As expected, the model predicts rather high NO conversion for both the dual-layer and dual-brick catalysts when both low space velocity and low diffusivity ratio (or high washcoat diffusivity) are used. A $\lambda$-value of 10 corresponds to the washcoat in which the bulk diffusion in the washcoat is dominant and in which the diffusional limitations are minimal. Interestingly, it can be observed in comparing Fig.8(a) and 7(a) that increasing the diffusivity of the reactants in the washcoat can be detrimental at higher temperature in the dual-layer configuration because of the enhanced oxidation of $\mathrm{NH}_{3}$ by $\mathrm{O}_{2}$, which is not desirable. So, on the one hand, enhancing the washcoat 
diffusion process increases the NO conversion at intermediate temperatures (when washcoat diffusion is important, as for $\lambda=100$, as shown in earlier cases) but, on the other hand, it lowers the performance at high temperatures by promoting the detrimental $\mathrm{NH}_{3}$ oxidation side reaction. Similar to the previous case $(\lambda=100$ and SV0.5, Fig $6(\mathrm{~b}))$, nearly complete conversion of NO is predicted for the dual-brick configuration at higher temperatures. The computed values of function, $f$, shown in Fig 9(a) clearly indicate that the dual-brick gives higher conversion than dual-layer under these conditions. Finally, the simulations with high space velocity (SV5) and high washcoat diffusivity $(\lambda=10)$ shows that for lower loading of Fe-SCR catalyst similar performance in term of NO conversion is achieved for both dual-layer and dual-brick configurations. However, at higher Fe- loading the dual-layer gives comparatively higher NO conversion at lower to intermediate temperatures (Fig 8(c and d)). This is due to a lack of sufficient contact time in the Cu-SCR brick in the dual-brick configuration. It can also be deduced from Fig 9 (b) where the values of objective function, $f$, for the dual-layer catalyst are smaller than those for the dual-brick catalyst for the higher Fe-SCR fraction. This analysis clearly indicates that except during very high space velocity operation the dual-brick configuration gives overall better performance than the dual-layer catalyst.

\section{$7 \quad$ Concluding remarks}

Simulation studies of combined $\mathrm{Fe} / \mathrm{Cu}-\mathrm{SCR}$ catalysts have been carried out to determine the composition (fraction of washcoat loading) and architecture (layered versus brick) that gives a high NO conversion over a wide range of conditions. The simulations also provide insight into the coupling of transport and reaction. Specifically, we have studied the effect of washcoat loading of individual SCR components (i.e. Fe- and $\mathrm{Cu}-\mathrm{SCR}$ ) and the effects of washcoat diffusivity and space velocity on the performance of the dual-layer and dual-brick catalysts. The 
sensitivity analyses of washcoat diffusivity and space velocity provided essential information in identifying conditions where one configuration gives better overall performance than the other.

The main finding of this work is that we have identified that under most operating conditions considered the dual-brick configuration outperforms the dual-layer counterpart over the temperature window of $100-600{ }^{\circ} \mathrm{C}$ (up to $6 \%$ higher $\mathrm{NO}$ conversion obtained for optimal dual-brick catalyst than dual-layer for base case conditions). In earlier experimental studies [8], it was not clear of which configuration was better largely due to the uncertainties in preparing the dual-layer catalysts. The results provided by Metkar et al., [8] showed very similar performance of the dual-layer and dual-brick catalysts. In this work, we have showed that the diffusional limitations in the dual-layer catalyst at the intermediate temperature leads to overall lower NO conversion compared to the dual-brick catalyst. At intermediate temperature $\left(200-400{ }^{\circ} \mathrm{C}\right)$, the $\mathrm{Cu}-\mathrm{SCR}$ catalyst is more active than Fe-SCR so expectedly diffusional limitations in the $\mathrm{Cu}$-SCR catalyst are more significant than in the Fe-SCR catalyst. As a result, the Fe-SCR layer coated on top of the $\mathrm{Cu}-\mathrm{SCR}$ layer creates an additional diffusional barrier, lowering the effective activity of the Cu-SCR catalyst. Because the activity of the combined system is largely contributed by $\mathrm{Cu}-\mathrm{SCR}$ catalyst in the intermediate temperature range, the overall NO conversion of the combined system is lowered. The dual-brick configuration does not have such additional diffusive barrier so the NO conversion is higher. For the base case simulation i.e. $\lambda=100$ and SV $=57,000 \mathrm{hr}^{-1}$, the optimal loading of the catalyst or percent content of Fe-SCR catalyst was found to be $5 \%(=5 \mu \mathrm{m})$ and $20 \%(=0.2 \mathrm{~cm})$ for the dual-layer and dual-brick catalysts, respectively. However, the optimal configuration was found to be the brick configurations as it gave better performance for the entire range of catalyst composition. 
Simulations of dual-layer and dual-brick catalyst with different washcoat diffusivities and space velocities show that dual-layer perform better than dual-brick only in the case of high space velocity and minimal washcoat diffusional limitations. Under these conditions, the residence time in the individual catalyst bricks in the dual-brick system is rather small compared to that in the dual-layer for which both catalytic components are distributed throughout the catalyst length. However, the apparent activity of the combined system under these conditions (high space velocity) may be lower than the Cu-only SCR catalyst so the addition of Fe would be moot. It is noted that the space velocity used in those simulations are rather high and it is very unlikely that the real system under normal operating conditions would operate at such high SV $\left(\right.$ ca. $300 \mathrm{k} \mathrm{h}^{-1}$ ). Finally, the conclusions drawn about the relative merits of the dual-layer versus sequential monolith designs will depend on the total washcoat loading (thickness) and the breadth of the temperature window encompassing the two catalysts of different activities. The temperature range considered in this study was rather wide and spanned the kinetic, washcoat diffusion, and external diffusion controlling regimes. Were the total washcoat loading (thickness) lower, and the temperature window narrower and located more centrally in the higher temperature regime, the dual layer catalyst would be more attractive.

\section{Acknowledgement}

This work was supported by grants from the Department of Energy Office of Vehicle Technologies DOE-NETL (DE-EE0000205) and National Science Foundation (CBET 1258688).

\section{Nomenclature:}

a width/hydraulic diameter of the channel (m)

$\mathrm{A}_{\mathrm{bi}} \quad$ reverse pre-exponential factor for reaction $\mathrm{i}$

$\mathrm{A}_{\mathrm{fi}} \quad$ forward pre-exponential factor for reaction $\mathrm{i}$

$\mathrm{C}_{\mathrm{tm}} \quad$ total gas concentration $\left(\mathrm{mol} / \mathrm{m}^{3}\right)$

$\mathrm{C}_{\mathrm{S} 1}$ concentration of $\mathrm{NH}_{3}$ adsorption (Brønsted) sites $\left(\mathrm{mol} / \mathrm{m}_{\mathrm{wc}}^{3}\right)$ 
$\begin{array}{ll}\mathrm{C}_{\mathrm{S} 2} & \text { concentration of secondary } \mathrm{NH}_{3} \text { adsorption si } \\ \mathrm{D}_{\mathrm{f}} & \text { diffusivity of species in the fluid phase }\left(\mathrm{m}^{2} / \mathrm{s}\right)\end{array}$

$D_{e}$ effective diffusivity of species in the washcoat $\left(\mathrm{m}^{2} / \mathrm{s}\right)$

$\mathrm{E}_{\mathrm{bi}} \quad$ reverse activation energy for reaction $\mathrm{i}$

$\mathrm{E}_{\mathrm{fi}} \quad$ forward activation energy for reaction $\mathrm{i}$

$\mathrm{k}_{\mathrm{bi}} \quad$ reverse reaction rate constant for reaction $\mathrm{i}$

$\mathrm{k}_{\mathrm{fi}} \quad$ forward reaction rate constant for reaction i

$\mathrm{k}_{\mathrm{me}} \quad$ external mass transfer coefficient $(\mathrm{m} / \mathrm{s})$

$\mathrm{L} \quad$ length of the monolith (m)

$\mathrm{P}$ transverse Peclet number

$\mathrm{R}_{\mathrm{r}} \quad$ reaction rate $\left(\mathrm{mol} / \mathrm{m}^{3} / \mathrm{s}\right)$ of reaction $r$

$\mathrm{R}_{\Omega_{1}} \quad$ effective transverse diffusion length for flow area (m)

$\mathrm{R}_{\Omega_{2}} \quad$ effective transverse diffusion length for washcoat area (m)

$\mathrm{Sh}_{\mathrm{e}} \quad$ external Sherwood number

$\mathrm{t}$ time (s)

$\mathrm{T}$ monolith temperature $(\mathrm{K})$

$\langle\mathrm{u}\rangle \quad$ average fluid velocity in the fluid phase $(\mathrm{m} / \mathrm{s})$

$\mathrm{x}_{\mathrm{fm}, \mathrm{j}} \quad$ cup-mixing mole fraction of species $\mathrm{j}$ in fluid phase

$\mathrm{x}_{\mathrm{s}, \mathrm{j}} \quad$ mole fraction of species $\mathrm{j}$ in the washcoat/fluid interface

$\mathrm{x}_{\mathrm{wc}, \mathrm{j}}$ mole fraction of species $\mathrm{j}$ in the washcoat

y length co-ordinate along radial (washcoat) direction (m)

$\mathrm{z}$ length co-ordinate along axial direction (m)

\section{Greek letters}

$\lambda$ diffusivity ratio

$\Gamma \quad$ site concentration $\left(\mathrm{C}_{\mathrm{s} 1, \mathrm{Fe}}, \mathrm{C}_{\mathrm{s} 2, \mathrm{Fe}}, \mathrm{C}_{\mathrm{s} 1, \mathrm{Cu}}\right)\left(\mathrm{mol} / \mathrm{m}_{\mathrm{wc}}^{3}\right)$

$\vartheta_{j r} \quad$ stoichiometric coefficient of species $j$ for reaction $r$

$\theta_{k} \quad$ fractional surface coverage of species $\mathrm{k}$

$\varepsilon_{\mathrm{wc}} \quad$ porosity of washcoat 


\section{References}

[1] D.W. Fickel, E. D'Addio, J.A. Lauterbach, R.F. Lobo, The ammonia selective catalytic reduction activity of copper-exchanged small-pore zeolites, Applied Catalysis B: Environmental, 102 (2011) 441-448.

[2] K. Kamasamudram, N.W. Currier, X. Chen, A. Yezerets, Overview of the practically important behaviors of zeolite-based urea-SCR catalysts, using compact experimental protocol, Catalysis Today, 151 (2010) 212-222.

[3] P.S. Metkar, M.P. Harold, V. Balakotaiah, Experimental and kinetic modeling study of $\mathrm{NH}_{3}$ SCR of NOx on Fe-ZSM-5, Cu-chabazite and combined Fe- and Cu-zeolite monolithic catalysts, Chemical Engineering Science, 87 (2013) 51-66.

[4] P.S. Metkar, N. Salazar, R. Muncrief, V. Balakotaiah, M.P. Harold, Selective catalytic reduction of $\mathrm{NO}$ with $\mathrm{NH}_{3}$ on iron zeolite monolithic catalysts: Steady-state and transient kinetics, Applied Catalysis B: Environmental, 104 (2011) 110-126.

[5] A. Grossale, I. Nova, E. Tronconi, D. Chatterjee, M. Weibel, The chemistry of the $\mathrm{NO} / \mathrm{NO}_{2}-$ $\mathrm{NH}_{3}$ "fast" SCR reaction over Fe-ZSM5 investigated by transient reaction analysis, Journal of Catalysis, 256 (2008) 312-322.

[6] I. Nova, C. Ciardelli, E. Tronconi, D. Chatterjee, B. Bandl-Konrad, $\mathrm{NH}_{3}-\mathrm{NO} / \mathrm{NO}_{2}$ chemistry over V-based catalysts and its role in the mechanism of the Fast SCR reaction, Catalysis Today, 114 (2006) 3-12.

[7] E. Tronconi, I. Nova, C. Ciardelli, D. Chatterjee, M. Weibel, Redox features in the catalytic mechanism of the "standard" and "fast" $\mathrm{NH}_{3}$-SCR of NOx over a V-based catalyst investigated by dynamic methods, Journal of Catalysis, 245 (2007) 1-10.

[8] P.S. Metkar, M.P. Harold, V. Balakotaiah, Selective catalytic reduction of NOx on combined Fe- and $\mathrm{Cu}-z e o l i t e$ monolithic catalysts: Sequential and dual layer configurations, Applied Catalysis B: Environmental, 111-112 (2012) 67-80.

[9] M. Devadas, O. Kröcher, M. Elsener, A. Wokaun, N. Söger, M. Pfeifer, Y. Demel, L. Mussmann, Influence of $\mathrm{NO}_{2}$ on the selective catalytic reduction of $\mathrm{NO}$ with ammonia over Fe-ZSM5, Applied Catalysis B: Environmental, 67 (2006) 187-196.

[10] A. Grossale, I. Nova, E. Tronconi, D. Chatterjee, M. Weibel, $\mathrm{NH}_{3}-\mathrm{NO} / \mathrm{NO}_{2} \mathrm{SCR}$ for Diesel Exhausts Aftertreatment: Reactivity, Mechanism and Kinetic Modelling of Commercial Fe- and Cu-Promoted Zeolite Catalysts, Top Catal, 52 (2009) 1837-1841.

[11] M. Colombo, I. Nova, E. Tronconi, A comparative study of the $\mathrm{NH}_{3}-\mathrm{SCR}$ reactions over a Cu-zeolite and a Fe-zeolite catalyst, Catalysis Today, 151 (2010) 223-230.

[12] J. Girard, G. Cavataio, R. Snow, C. Lambert, Combined Fe-Cu SCR Systems with Optimized Ammonia to NOx Ratio for Diesel NOx Control, SAE International Journal of Fuels and Lubricants, 1 (2009) 603-610.

[13] O. Kro $\square$ cher, M. Elsener, Combination of $\mathrm{V}_{2} \mathrm{O}_{5} / \mathrm{WO}_{3}-\mathrm{TiO}_{2}, \mathrm{Fe}-\mathrm{ZSM} 5$, and $\mathrm{Cu}-\mathrm{ZSM} 5$ Catalysts for the Selective Catalytic Reduction of Nitric Oxide with Ammonia, Industrial \& Engineering Chemistry Research, 47 (2008) 8588-8593.

[14] P.S. Metkar, V. Balakotaiah, M.P. Harold, Experimental study of mass transfer limitations in $\mathrm{Fe}$ - and $\mathrm{Cu}$-zeolite-based $\mathrm{NH}_{3} \mathrm{SCR}$ monolithic catalysts, Chemical Engineering Science, 66 (2011) 5192-5203.

[15] A.C. Hindmarsh, ODEPACK, A Systematized Collection of ODE Solvers, R. S. Stepleman et al. (eds.), North-Holland, Amsterdam, (vol. 1 of ), pp. 55-64, IMACS Transactions on Scientific Computation, 1 (1983) 55-64. 
[16] M. Colombo, I. Nova, E. Tronconi, Detailed kinetic modeling of the $\mathrm{NH}_{3}-\mathrm{NO} / \mathrm{NO}_{2} \mathrm{SCR}$ reactions over a commercial Cu-zeolite catalyst for Diesel exhausts after treatment, Catalysis Today, 197 (2012) 243-255.

[17] M. Colombo, I. Nova, E. Tronconi, V. Schmeißer, B. Bandl-Konrad, L. Zimmermann, $\mathrm{NO} / \mathrm{NO}_{2} / \mathrm{N}_{2} \mathrm{O}-\mathrm{NH}_{3}$ SCR reactions over a commercial Fe-zeolite catalyst for diesel exhaust aftertreatment: Intrinsic kinetics and monolith converter modelling, Applied Catalysis B: Environmental, 111-112 (2012) 106-118.

[18] P.S. Metkar, V. Balakotaiah, M.P. Harold, Experimental and kinetic modeling study of NO oxidation: Comparison of $\mathrm{Fe}$ and $\mathrm{Cu}$-zeolite catalysts, Catalysis Today, 184 (2012) 115128.

[19] V. Balakotaiah, D.H. West, Shape normalization and analysis of the mass transfer controlled regime in catalytic monoliths, Chemical Engineering Science, 57 (2002) 1269-1286. 

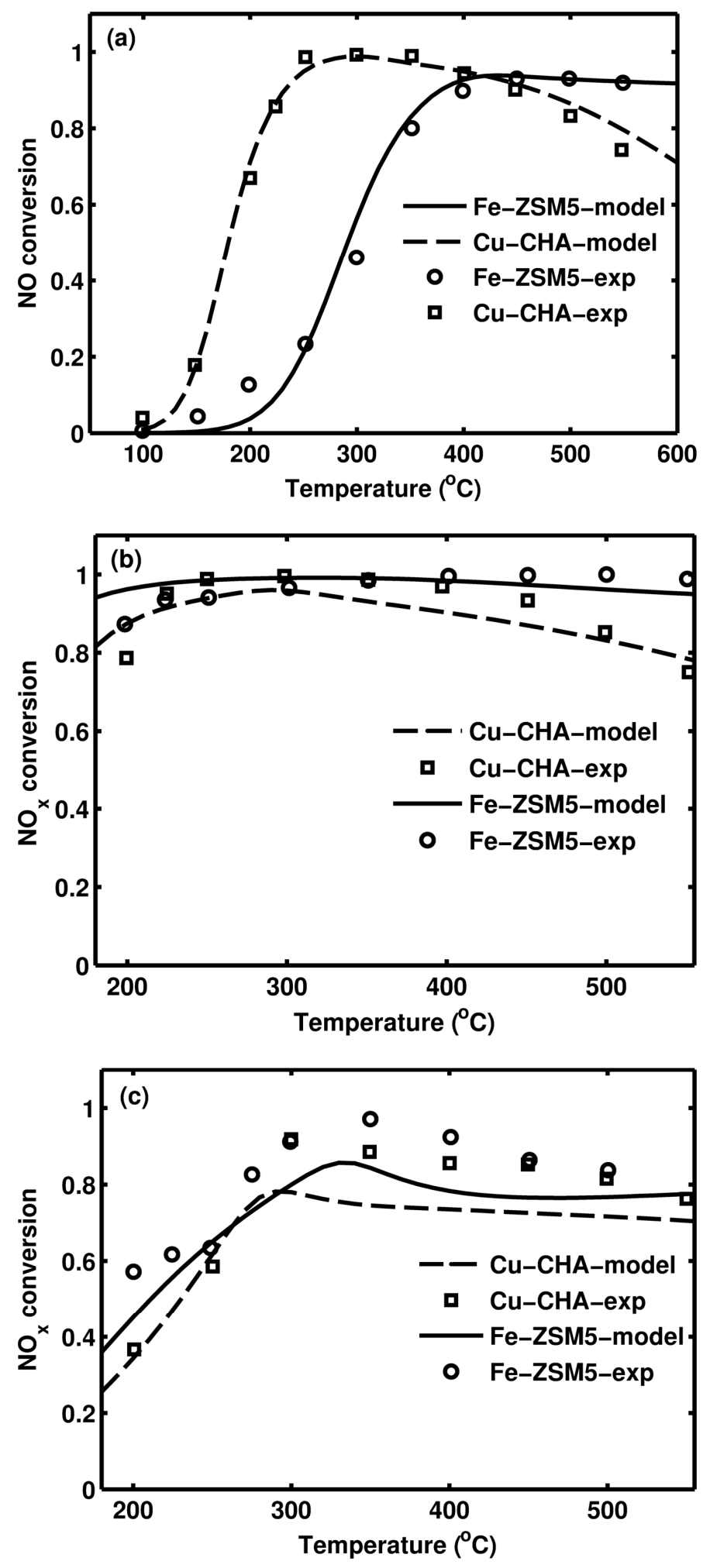

Figure 1 Experimental and model-predicted steady-state NOx conversion as a function of temperature under (a) standard SCR (b) fast SCR and (c) $\mathrm{NO}_{2}$-SCR reaction conditions; These results have been reproduced by using kinetic parameters provided in [3] 

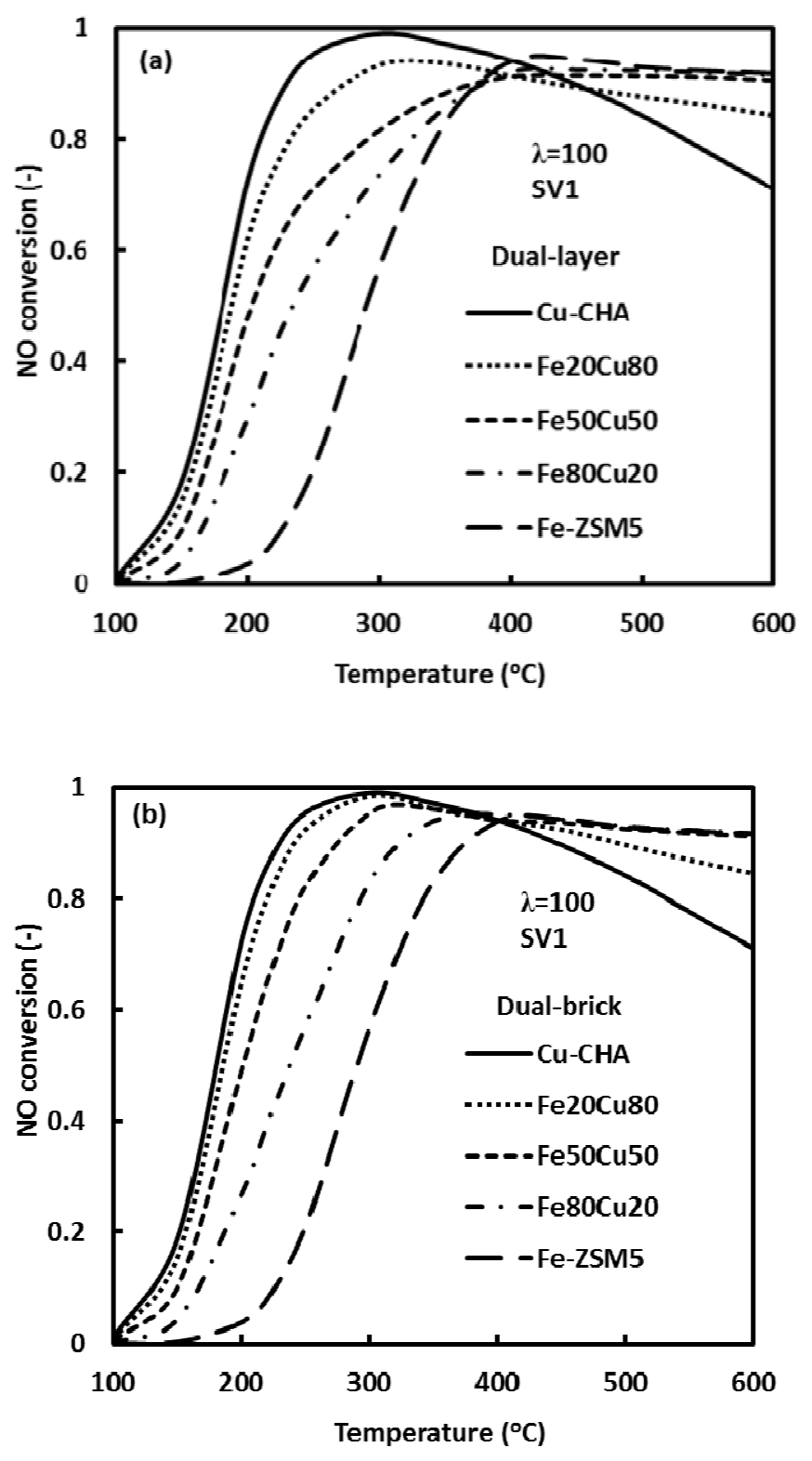

Figure 2 Model-predicted NO conversion as a function of temperature under standard SCR conditions (a) dual-layer (b) dual-brick Fe/+Cu SCR catalyst; Conditions: feed=500 ppm NO, $500 \mathrm{ppm} \mathrm{NH}_{3}, 5 \% \mathrm{O}_{2}, 2 \% \mathrm{H}_{2} \mathrm{O}$ in balance Ar; GHSV $=57,000 \mathrm{hr}^{-1}$ (SV1); monolith length = 2 $\mathrm{cm}$; total washcoat thickness $=50 \mu \mathrm{m}$; diffusivity ratio $(\lambda)=100$ 


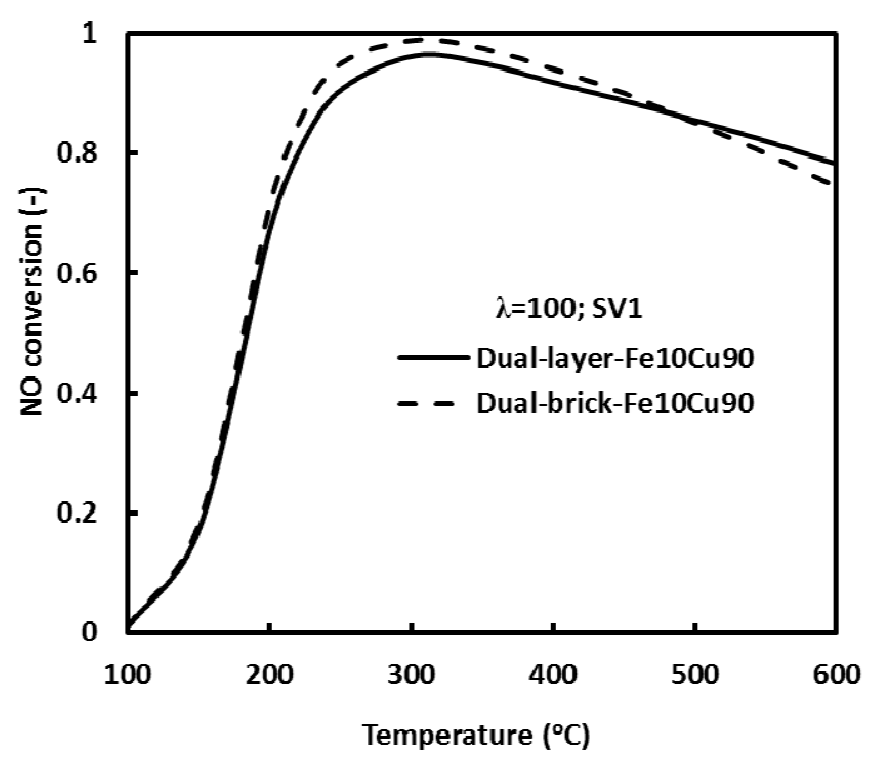

Figure 3 Model-predicted NO conversion as a function of temperature under standard SCR conditions over dual-layer and dual-brick $\mathrm{Fe} /+\mathrm{Cu} \mathrm{SCR}$ (10\% Fe-) catalyst; Conditions: feed=500 ppm NO, $500 \mathrm{ppm} \mathrm{NH}_{3}, 5 \% \mathrm{O}_{2}, 2 \% \mathrm{H}_{2} \mathrm{O}$ in balance Ar; GHSV $=57,000 \mathrm{hr}^{-1}$ (SV1); monolith length $=2 \mathrm{~cm}$; total washcoat thickness $=50 \mu \mathrm{m}$; diffusivity ratio $(\lambda)=100$. 

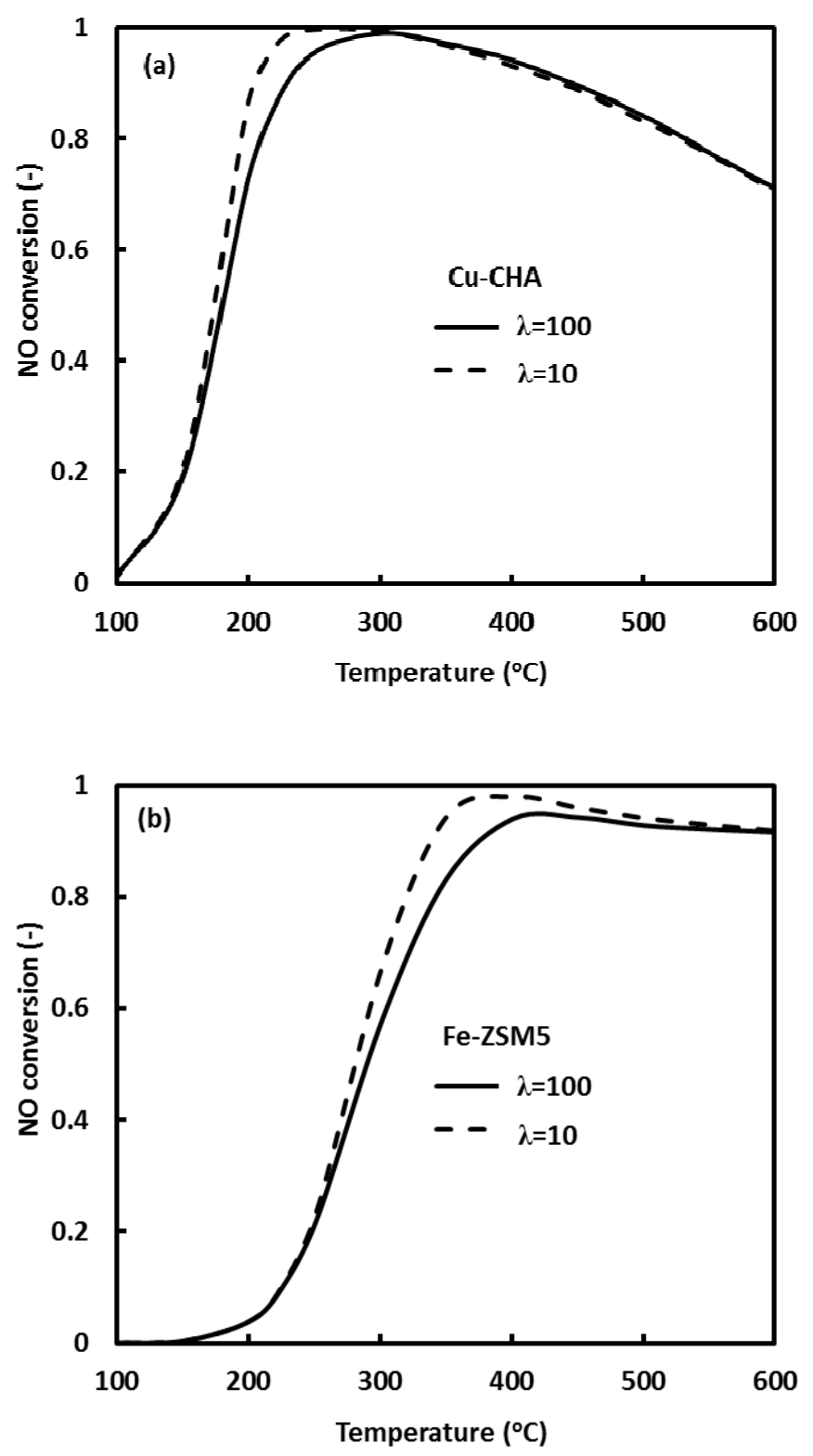

Figure 4 Model-predicted steady-state NO conversion under standard SCR reaction condition for diffusivity ratios $\left(\lambda=\mathrm{D}_{\mathrm{f}} / \mathrm{D}_{\mathrm{e}}\right)$ of 10 and 100. The difference in NO conversion is observed over the temperature range where washcoat diffusion becomes important. Conditions: feed $=500$ ppm NO, 500 ppm $\mathrm{NH}_{3}, 5 \% \mathrm{O}_{2}, 2 \% \mathrm{H}_{2} \mathrm{O}$ in balance Ar; GHSV = 57,000 hr ${ }^{-1}$ (SV1); monolith length $=2 \mathrm{~cm}$; total washcoat thickness $=50 \mu \mathrm{m}$; diffusivity ratio $(\lambda)=10$ or 100 . 

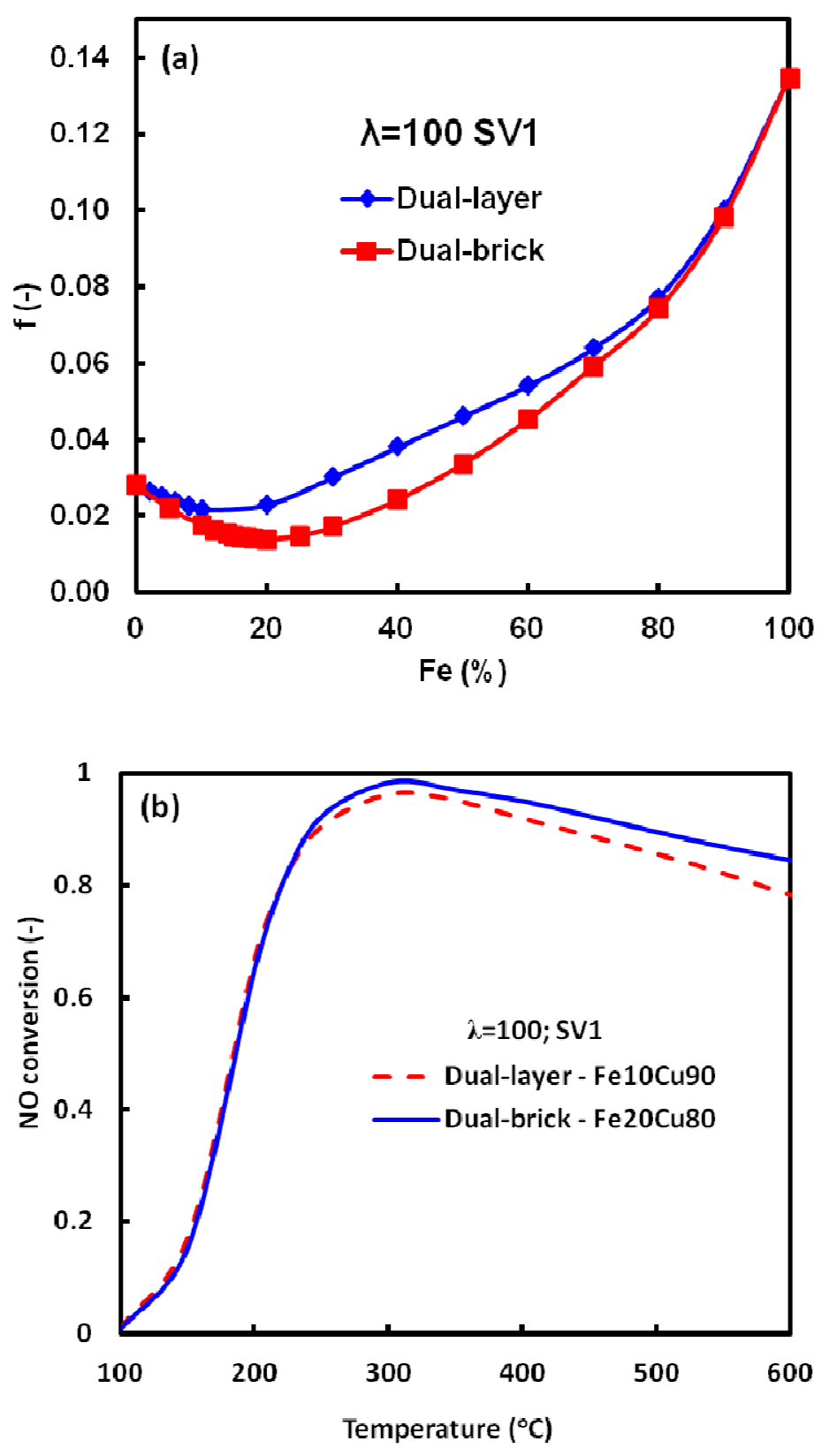

Figure 5 (a) Simulated values of "f" as a function of different fraction of Fe-ZSM5 catalyst in the combined $\mathrm{Cu} / \mathrm{Fe}$ system; (b) Model-predicted NO conversion as a function of temperature for optimal dual-layer and dual-brick catalyst. Conditions: feed=500 ppm NO, $500 \mathrm{ppm} \mathrm{NH}_{3}, 5 \%$ $\mathrm{O}_{2}, 2 \% \mathrm{H}_{2} \mathrm{O}$ in balance Ar; GHSV $=57,000 \mathrm{hr}^{-1}(\mathrm{SV} 1)$; monolith length $=2 \mathrm{~cm}$; total washcoat thickness $=50 \mu \mathrm{m}$; diffusivity ratio $(\lambda)=100$. 

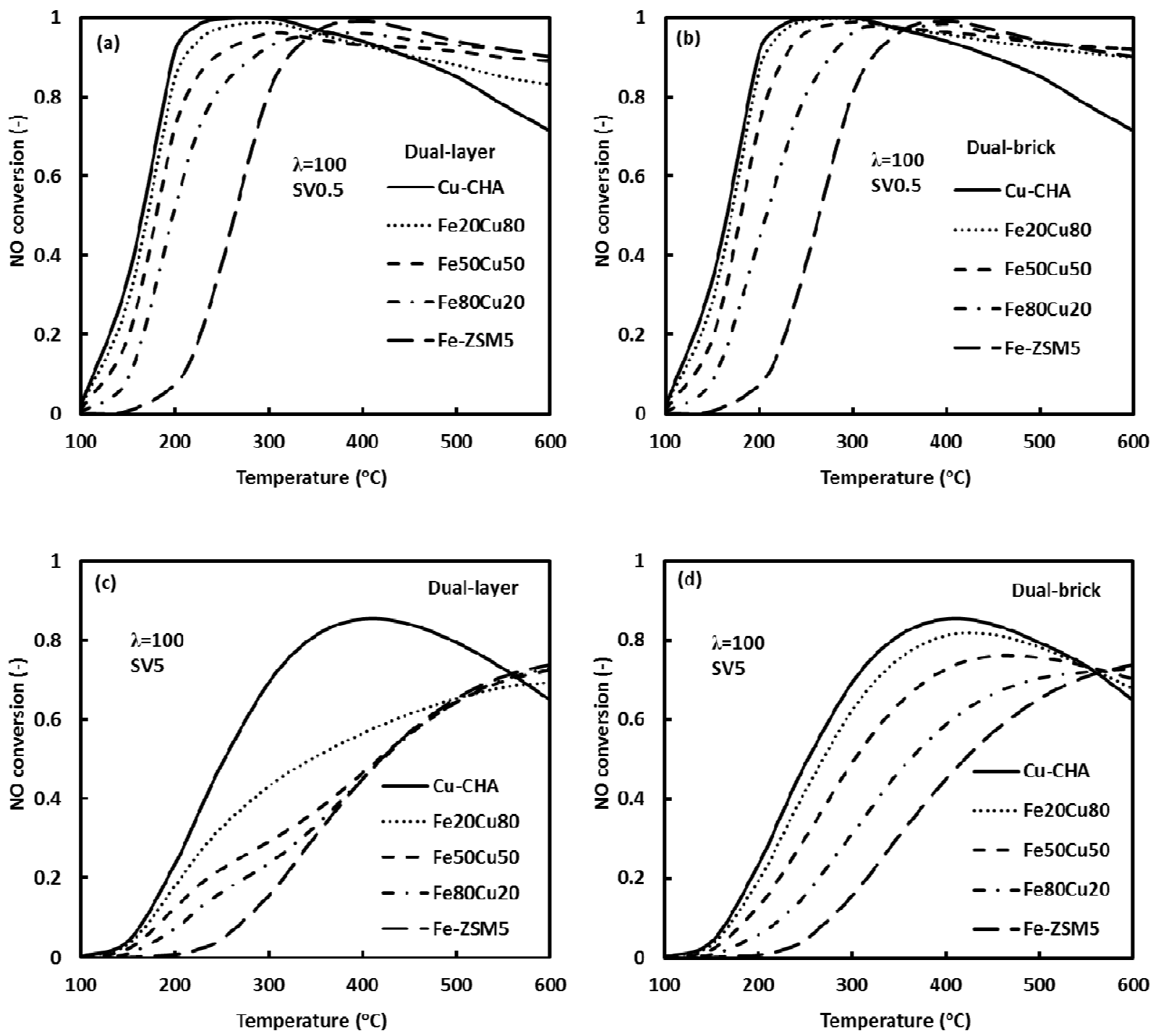

Figure 6 Model-predicted NO conversion as a function of temperature under standard SCR conditions over different combined $\mathrm{Fe} / \mathrm{Cu}$ SCR catalysts - (a) dual-layer, GHSV $=0.5 \times 57,000 \mathrm{hr}^{-}$ ${ }^{1}$ (SV0.5), (b) dual-brick GHSV $=0.5 \times 57,000 \mathrm{hr}^{-1}$ (SV0.5), (c) dual-layer, GHSV $=5 \times 57,000 \mathrm{hr}^{-1}$ (SV5) (d) dual-brick GHSV $=5 \times 57,000 \mathrm{hr}^{-1}$ (SV5); Conditions: feed $=500 \mathrm{ppm}$ NO, $500 \mathrm{ppm}$ $\mathrm{NH}_{3}, 5 \% \mathrm{O}_{2}, 2 \% \mathrm{H}_{2} \mathrm{O}$ in balance Ar; monolith length $=2 \mathrm{~cm}$; total washcoat thickness $=50 \mu \mathrm{m}$; diffusivity ratio $(\lambda)=100$ 

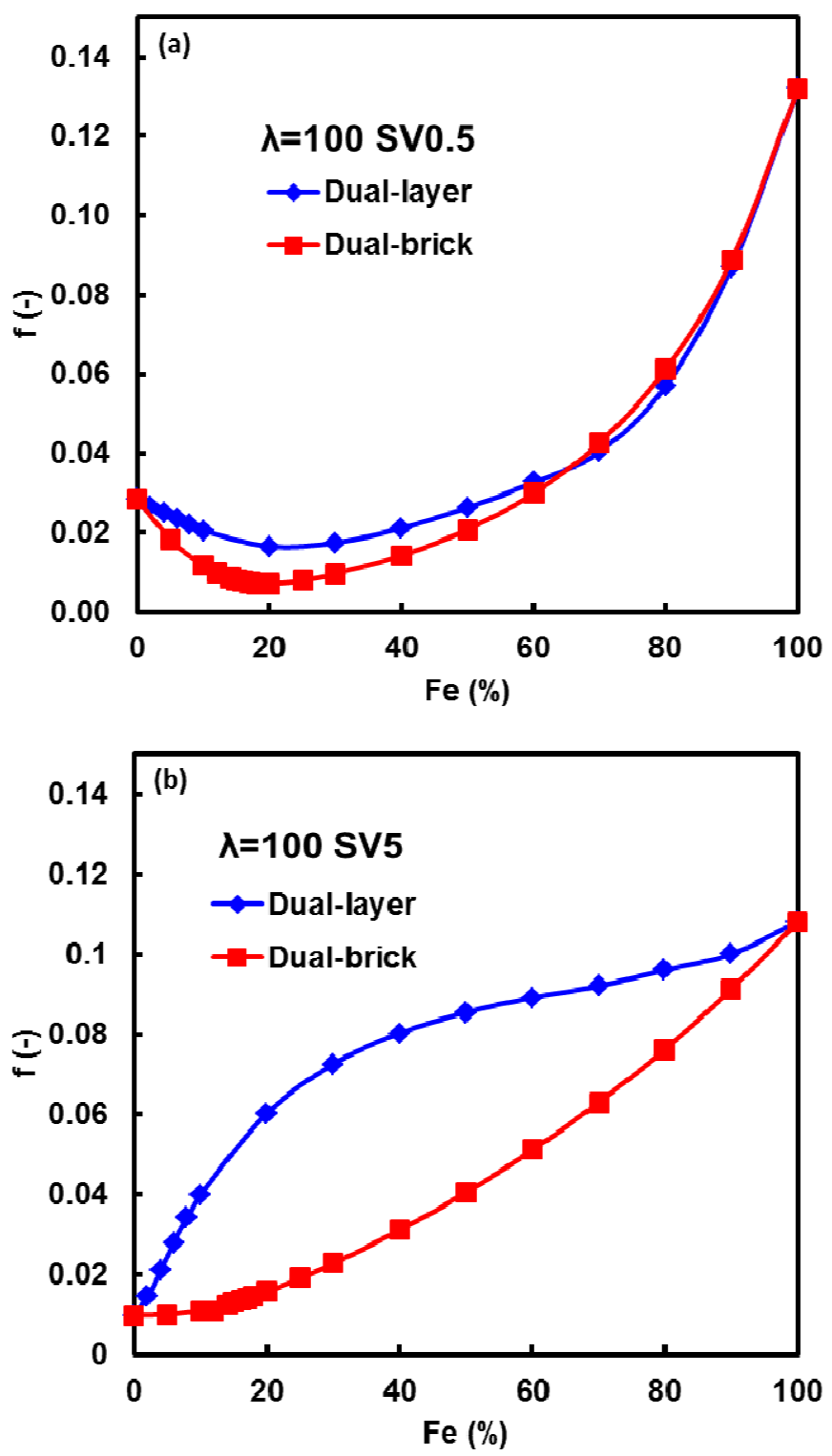

Figure 7 Simulated values of "f" as a function of different fraction of Fe-ZSM5 catalyst in the combined $\mathrm{Cu} / \mathrm{Fe}$ system with (a) GHSV $=0.5 \times 57,000 \mathrm{hr}^{-1}(\mathrm{SV} 0.5)$ (b) GHSV $=5 \times 57,000 \mathrm{hr}^{-1}$ (SV5); Conditions: feed=500 ppm NO, $500 \mathrm{ppm} \mathrm{NH}_{3}, 5 \% \mathrm{O}_{2}, 2 \% \mathrm{H}_{2} \mathrm{O}$ in balance Ar; monolith length $=2 \mathrm{~cm}$; total washcoat thickness $=50 \mu \mathrm{m} ;$ diffusivity ratio $(\lambda)=100$ 

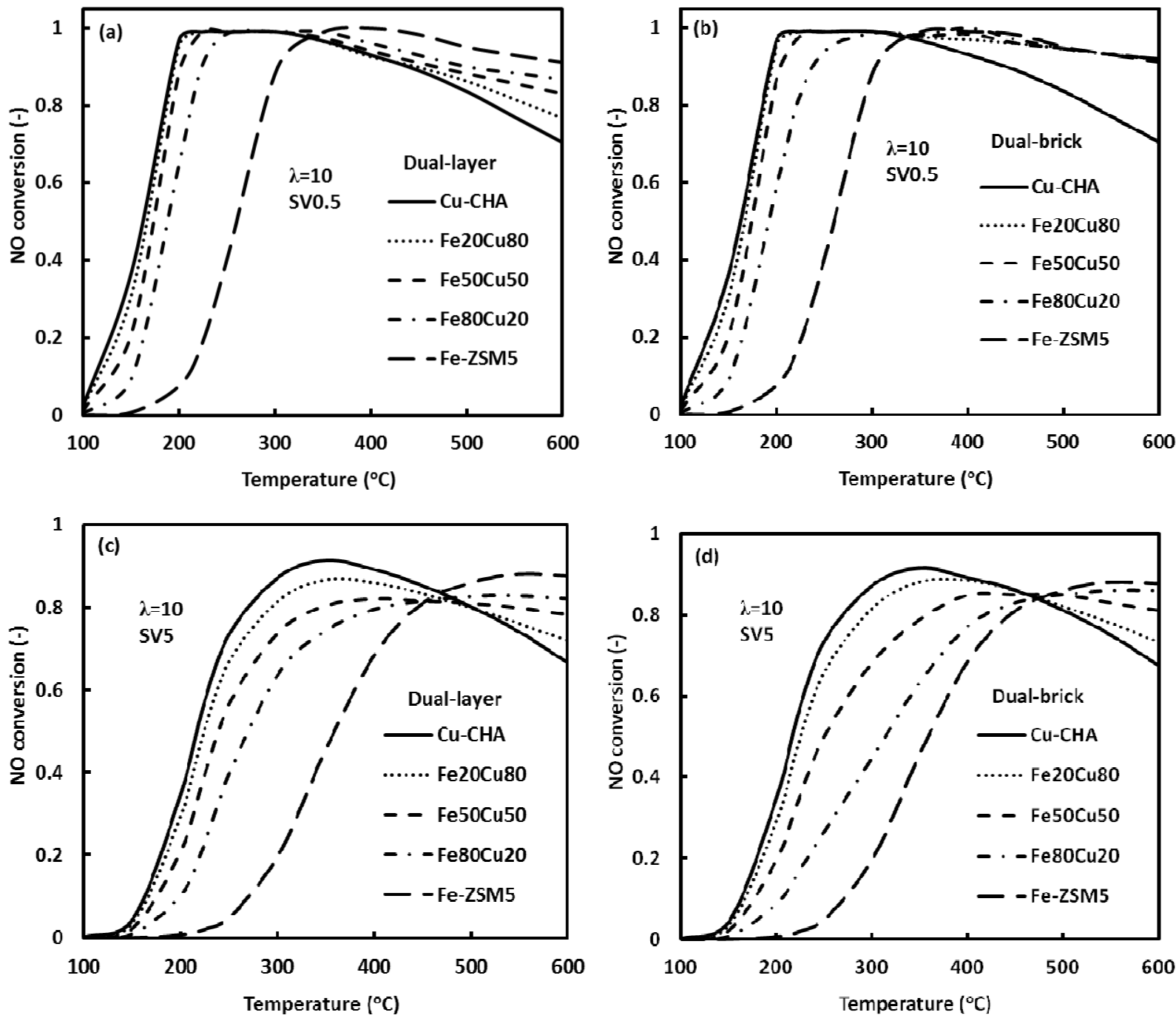

Figure 8 Model-predicted NO conversion as a function of temperature under standard SCR conditions over different combined Fe/Cu SCR catalysts - (a) dual-layer, GHSV $=0.5 \times 57,000 \mathrm{hr}^{-}$ ${ }^{1}$ (SV0.5), (b) dual-brick GHSV = 0.5 $\times 57,000 \mathrm{hr}^{-1}$ (SV0.5), (c) dual-layer, GHSV = 5×57,000 hr ${ }^{-1}$ (SV5) (d) dual-brick GHSV $=5 \times 57,000 \mathrm{hr}^{-1}$ (SV5) ; Conditions: feed $=500$ ppm NO, $500 \mathrm{ppm}$ $\mathrm{NH}_{3}, 5 \% \mathrm{O}_{2}, 2 \% \mathrm{H}_{2} \mathrm{O}$ in balance Ar; monolith length $=2 \mathrm{~cm}$; total washcoat thickness = 50 $\mu \mathrm{m}$; diffusivity ratio $(\lambda)=10$ 

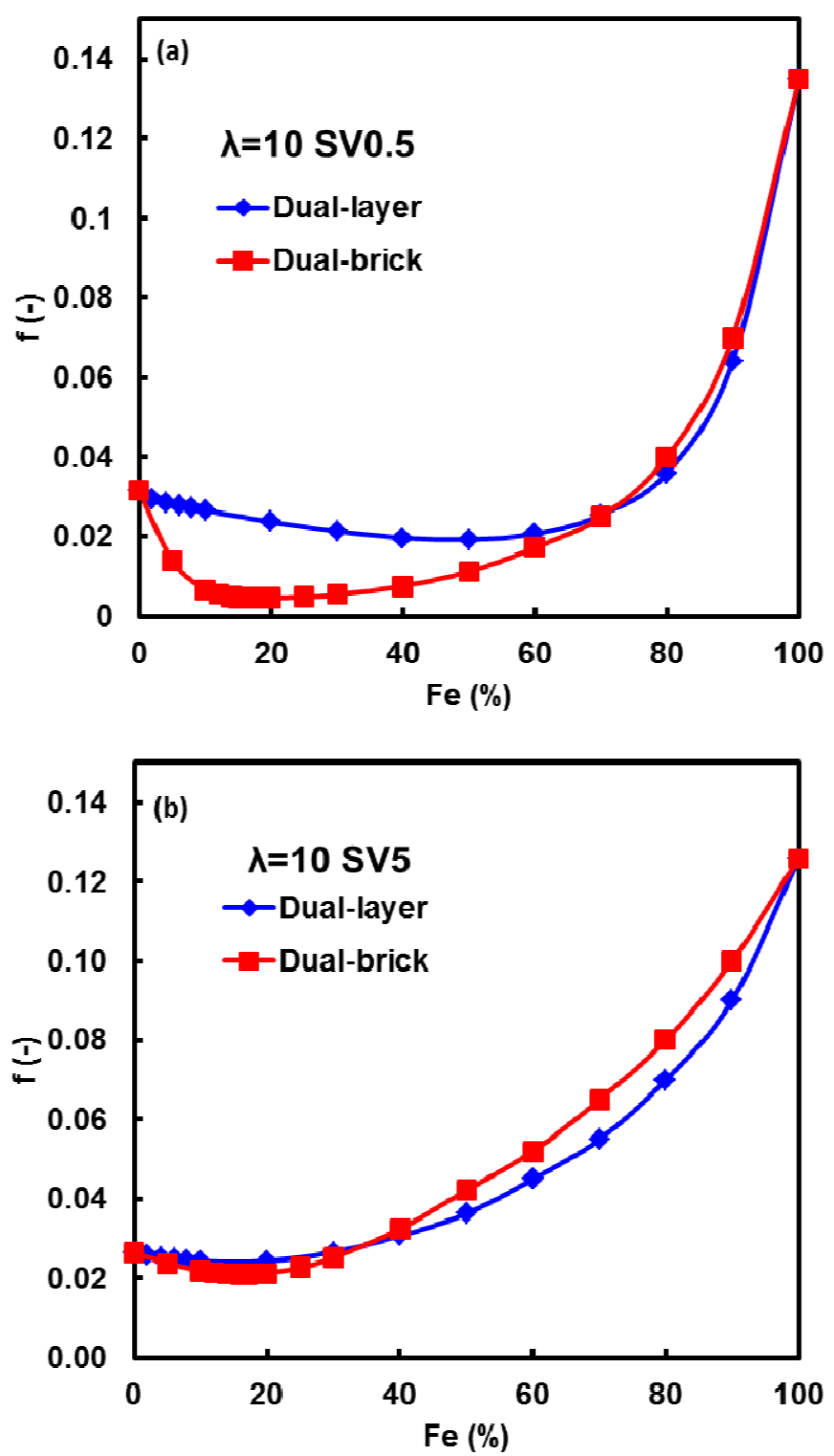

Figure 9 Simulated values of "f" as a function of different fraction of Fe-ZSM5 catalyst in the combined Cu/Fe system with (a) GHSV $=0.5 \times 57,000 \mathrm{hr}^{-1}(\mathrm{SV} 0.5)$ (b) GHSV $=5 \times 57,000 \mathrm{hr}^{-1}$ (SV5); Conditions: feed $=500$ ppm NO, $500 \mathrm{ppm} \mathrm{NH}_{3}, 5 \% \mathrm{O}_{2}, 2 \% \mathrm{H}_{2} \mathrm{O}$ in balance Ar; monolith length $=2 \mathrm{~cm}$; total washcoat thickness $=50 \mu \mathrm{m} ;$ diffusivity ratio $(\lambda)=10$ 


Table 1 Constant parameters used
\begin{tabular}{|c|c|}
\hline Parameter & Value \\
\hline $\mathrm{a}$ & $1.1 \mathrm{~mm}$ \\
\hline $\mathrm{C}_{\mathrm{s} 1, \mathrm{Fe}}$ & $3000 \mathrm{~mol} / \mathrm{m}^{3}{ }_{\mathrm{wc}}$ \\
\hline $\mathrm{C}_{\mathrm{s} 2, \mathrm{Fe}}$ & $500 \mathrm{~mol} / \mathrm{m}^{3}{ }_{\mathrm{wc}}$ \\
\hline $\mathrm{C}_{\mathrm{s} 1, \mathrm{Cu}}$ & $4000 \mathrm{~mol} / \mathrm{m}^{3}{ }_{\mathrm{wc}}$ \\
\hline $\mathrm{L}$ & $2 \mathrm{~cm}$ \\
\hline $\mathrm{Sh}_{\mathrm{e}}$ & 3.608 \\
\hline$\square_{\mathrm{wc}}$ & 0.4 \\
\hline$\lambda$ & 100 \\
\hline $\mathrm{R}_{\Omega 1}$ & $2.5 \times 10^{-4} \mathrm{~m}$ \\
\hline $\mathrm{R}_{\Omega 2}$ & $5 \times 10^{-5} \mathrm{~m}$ \\
\hline
\end{tabular}

Table 2 Temperature dependent parameters used in the simulation

\begin{tabular}{|l|l|}
\hline Parameter & Value / Expression \\
\hline$\langle u\rangle$ & $4.05 \times 10^{-1} \times\left(\frac{\mathrm{T}}{273.15}\right) \mathrm{m} / \mathrm{s}$ \\
\hline $\mathrm{C}_{\mathrm{tm}}$ & $\frac{1000}{0.082 \times \mathrm{T}} \mathrm{mol} / \mathrm{m}^{3}$ \\
\hline $\mathrm{D}_{\mathrm{f}, \mathrm{NO}}$ & $1.24 \times 10^{-9} \times \mathrm{T}^{1.7006} \mathrm{~m}^{2} / \mathrm{s}$ \\
\hline $\mathrm{D}_{\mathrm{f}, \mathrm{NO} 2}$ & $0.79 \times 10^{-9} \times \mathrm{T}^{1.7297} \mathrm{~m}^{2} / \mathrm{s}$ \\
\hline $\mathrm{D}_{\mathrm{f}, \mathrm{N} 2}$ & $1.34 \times 10^{-9} \times \mathrm{T}^{1.6901} \mathrm{~m}^{2} / \mathrm{s}$ \\
\hline $\mathrm{D}_{\mathrm{f}, \mathrm{NH} 3}$ & $1.22 \times 10^{-9} \times \mathrm{T}^{1.7389} \mathrm{~m}^{2} / \mathrm{s}$ \\
\hline $\mathrm{D}_{\mathrm{f}, \mathrm{N} 2 \mathrm{O}}$ & $0.81 \times 10^{-9} \times \mathrm{T}^{1.7314} \mathrm{~m}^{2} / \mathrm{s}$ \\
\hline $\mathrm{D}_{\mathrm{f}, \mathrm{NH} 4 \mathrm{NO} 3}$ & $0.56 \times 10^{-9} \times \mathrm{T}^{1.7389} \mathrm{~m}^{2} / \mathrm{s}$ \\
\hline
\end{tabular}

Table 3 Reaction rate expressions [3]

\begin{tabular}{|c|l|l|}
\hline Reaction & \multicolumn{1}{|c|}{ Reaction } & \multicolumn{1}{|c|}{ Rate Expression } \\
\hline $\mathrm{R} 1$ & $\mathrm{NH}_{3}+\mathrm{S} 1 \leftrightarrow \mathrm{NH}_{3}-\mathrm{S} 1$ & $\mathrm{k}_{\mathrm{f} 1} \mathrm{X}_{\mathrm{NH} 3} \theta_{\mathrm{S} 1}-\mathrm{k}_{\mathrm{b} 1} \theta_{\mathrm{NH} 3-\mathrm{S} 1}$ \\
\hline $\mathrm{R} 2$ & $2 \mathrm{NH}_{3}-\mathrm{S} 1+1.5 \mathrm{O}_{2} \rightarrow \mathrm{N}_{2}+3 \mathrm{H}_{2} \mathrm{O}+2 \mathrm{~S} 1$ & $\mathrm{k}_{2 \mathrm{f}} \mathrm{X}_{\mathrm{O} 2} \theta_{\mathrm{NH} 3-\mathrm{S} 1}$ \\
\hline $\mathrm{R} 3$ & $\mathrm{NO}+1 / 2 \mathrm{O}_{2} \leftrightarrow \mathrm{NO}_{2}$ & $\mathrm{k}_{3 \mathrm{f}} \mathrm{X}_{\mathrm{O} 2}{ }^{0.5} \mathrm{X}_{\mathrm{NO}}-\mathrm{k}_{3 \mathrm{~b}} \mathrm{X}_{\mathrm{NO} 2}$ \\
\hline $\mathrm{R} 4$ & $4 \mathrm{NH}_{3}-\mathrm{S} 1+4 \mathrm{NO}_{2}+\mathrm{O}_{2} \rightarrow 4 \mathrm{~N}_{2}+6 \mathrm{H}_{2} \mathrm{O}+4 \mathrm{~S} 1$ & $\mathrm{k}_{4 \mathrm{f}} \mathrm{X}_{\mathrm{NO}} \theta_{\mathrm{NH} 3-\mathrm{S} 1} /\left(1+\mathrm{K}^{*} \mathrm{X}_{\mathrm{NH} 3}\right)$ \\
\hline $\mathrm{R} 5$ & $2 \mathrm{NH}_{3}-\mathrm{S} 1+\mathrm{NO}+\mathrm{NO}_{2} \rightarrow 2 \mathrm{~N}_{2}+3 \mathrm{H}_{2} \mathrm{O}+2 \mathrm{~S} 1$ & $\mathrm{k}_{5 \mathrm{f}} \mathrm{X}_{\mathrm{NO}} \mathrm{X}_{\mathrm{NO} 2} \theta_{\mathrm{NH} 3-\mathrm{S} 1}$ \\
\hline $\mathrm{R} 6$ & $4 \mathrm{NH}_{3}-\mathrm{S} 1+3 \mathrm{NO}_{2} \rightarrow 3.5 \mathrm{~N}_{2}+6 \mathrm{H}_{2} \mathrm{O}+4 \mathrm{~S} 1$ & $\mathrm{k}_{6 \mathrm{f}} \mathrm{X}_{\mathrm{NO} 2} \theta_{\mathrm{NH} 3-\mathrm{S} 1}$ \\
\hline $\mathrm{R} 7$ & $2 \mathrm{NH}_{3}-\mathrm{S} 1+2 \mathrm{NO}_{2} \rightarrow \mathrm{N}_{2}+\mathrm{NH}_{4} \mathrm{NO}_{3}+\mathrm{H}_{2} \mathrm{O}+2 \mathrm{~S} 1$ & $\mathrm{k}_{7 \mathrm{f}} \mathrm{X}_{\mathrm{NO} 2} \theta_{\mathrm{NH} 3-\mathrm{S} 1}$ \\
\hline $\mathrm{R} 8$ & $\mathrm{NH}_{4} \mathrm{NO}_{3} \rightarrow \mathrm{N}_{2} \mathrm{O}+2 \mathrm{H}_{2} \mathrm{O}$ & $\mathrm{k}_{8 \mathrm{f}} \mathrm{X}_{\mathrm{NH} 4 \mathrm{NO} 3}$ \\
\hline $\mathrm{R} 9$ & $2 \mathrm{~N}_{2} \mathrm{O} \rightarrow 2 \mathrm{~N}_{2}+\mathrm{O}_{2}$ & $\mathrm{k}_{9 \mathrm{f}} \mathrm{X}_{\mathrm{N} 2 \mathrm{O}}$ \\
\hline $\mathrm{R} 10$ & $2 \mathrm{NH}_{3}-\mathrm{S} 1+3 \mathrm{~N}_{2} \mathrm{O} \rightarrow 4 \mathrm{~N}_{2}+3 \mathrm{H}_{2} \mathrm{O}+2 \mathrm{~S} 1$ & $\mathrm{k}_{10 \mathrm{f}} \mathrm{X}_{\mathrm{N} 2 \mathrm{O}} \theta_{\mathrm{NH} 3-\mathrm{S} 1}$ \\
\hline $\mathrm{R} 11$ & $\mathrm{NH}_{3}+\mathrm{S} 2 \leftrightarrow \mathrm{NH}_{3}-\mathrm{S} 2$ & $\mathrm{k}_{\mathrm{f} 11} \mathrm{X}_{\mathrm{NH} 3} \theta_{\mathrm{S} 2}-\mathrm{k}_{\mathrm{b} 11} \theta_{\mathrm{NH} 3-\mathrm{S} 2}$ \\
\hline
\end{tabular}


Table 4 Reaction rate constants for $\mathrm{Cu}-\mathrm{CHA}$ and Fe-ZSM-5 catalysts [3]

\begin{tabular}{|c|c|c|c|c|c|}
\hline \multirow{2}{*}{ Parameter } & \multicolumn{2}{|c|}{ Values $\left(\mathrm{mol} /\left(\mathrm{m}_{\mathrm{wc}}{ }^{3} \mathrm{~s}\right)\right)$} & \multirow{2}{*}{ Parameter } & \multicolumn{2}{|c|}{ Values (kJ/mol) } \\
\hline & $\mathrm{Cu}-\mathrm{CHA}$ & Fe-ZSM-5 & & Cu-CHA & Fe-ZSM-5 \\
\hline $\mathrm{A}_{\mathrm{f} 1}$ & $6.68 \times 10^{7}$ & $1.70 \times 10^{8}$ & $E_{f 1}$ & 0 & 0 \\
\hline $\mathrm{A}_{\mathrm{b} 1}$ & $4.00 \times 10^{15}$ & $3.00 \times 10^{13}$ & $\mathrm{E}_{\mathrm{b} 1}$ & $145.9\left(1-0.98 \theta_{\mathrm{NH} 3-\mathrm{S} 1}\right)$ & $145.9\left(1-0.98 \theta_{\mathrm{NH} 3-\mathrm{S} 1}\right)$ \\
\hline $\mathrm{A}_{\mathrm{f} 2}$ & $5.56 \times 10^{16}$ & $7.16 \times 10^{7}$ & $E_{f 2}$ & 178.8 & 90.8 \\
\hline $\mathrm{A}_{\mathrm{f} 3}$ & $5.10 \times 10^{7}$ & $1.00 \times 10^{7}$ & $\mathrm{E}_{\mathrm{f} 3}$ & 56.0 & 48.0 \\
\hline $\mathrm{A}_{\mathrm{f} 4}$ & $7.08 \times 10^{13}$ & $2.46 \times 10^{10}$ & $E_{f 4}$ & 89.1 & 72.4 \\
\hline $\mathrm{A}_{\mathrm{f} 5}$ & $1.00 \times 10^{18}$ & $5.70 \times 10^{17}$ & $E_{f 5}$ & 77.1 & 68.1 \\
\hline $\mathrm{A}_{\mathrm{f} 6}$ & $1.96 \times 10^{17}$ & $2.13 \times 10^{16}$ & $\mathrm{E}_{\mathrm{f} 6}$ & 136.3 & 140.3 \\
\hline $\mathrm{A}_{\mathrm{f} 7}$ & $2.28 \times 10^{8}$ & $1.23 \times 10^{8}$ & $E_{\mathrm{f} 7}$ & 43.0 & 40.0 \\
\hline $\mathrm{A}_{\mathrm{f} 8}$ & $1.25 \times 10^{8}$ & $3.50 \times 10^{8}$ & $\mathrm{E}_{\mathrm{f} 8}$ & 41.5 & 37.0 \\
\hline $\mathrm{A}_{\mathrm{f} 9}$ & 0 & $4.50 \times 10^{11}$ & $\mathrm{E}_{\mathrm{f} 9}$ & 0 & 128.0 \\
\hline $\mathrm{A}_{\mathrm{f} 10}$ & 0 & $1.65 \times 10^{10}$ & $\mathrm{E}_{\mathrm{f} 10}$ & 0 & 90.0 \\
\hline $\mathrm{A}_{\mathrm{f} 11}$ & 0 & $1.00 \times 10^{6}$ & $E_{f 11}$ & 0 & 0 \\
\hline $\mathrm{A}_{\mathrm{b} 11}$ & 0 & $4.50 \times 10^{12}$ & $\mathrm{E}_{\mathrm{b} 11}$ & 0 & $130\left(1-0.45 \theta_{\mathrm{NH} 3-\mathrm{S} 2}\right)$ \\
\hline
\end{tabular}

